Revue des patrimoines

\title{
Des tranchées aux musées : l'archéologie pendant la Grande Guerre en Alsace et en Lorraine
}

Michaël Landolt, Bernadette Schnitzler, Jean-Claude Laparra, Franck Mourot et Jean-Pierre Legendre

\section{(2) OpenEdition \\ 12 Journals}

Édition électronique

URL : http://journals.openedition.org/insitu/10882

DOI : 10.4000/insitu.10882

ISSN : 1630-7305

Éditeur

Ministère de la Culture

Référence électronique

Michaël Landolt, Bernadette Schnitzler, Jean-Claude Laparra, Franck Mourot et Jean-Pierre Legendre,

"Des tranchées aux musées : I'archéologie pendant la Grande Guerre en Alsace et en Lorraine », In Situ [En ligne], 23 | 2014, mis en ligne le 03 mars 2014, consulté le 09 décembre 2019. URL : http:// journals.openedition.org/insitu/10882 ; DOI : 10.4000/insitu.10882

Ce document a été généré automatiquement le 9 décembre 2019.

In Situ Revues des patrimoines est mis à disposition selon les termes de la licence Creative Commons Attribution - Pas d'Utilisation Commerciale - Pas de Modification 4.0 International. 


\title{
Des tranchées aux musées : l'archéologie pendant la Grande Guerre en Alsace et en Lorraine
}

\author{
Michaël Landolt, Bernadette Schnitzler, Jean-Claude Laparra, Franck \\ Mourot et Jean-Pierre Legendre
}

«Mögen unsere elsässischen Schützengräben in
Vogesen und Rheinebene fernerhin abseits vom
blutigen Kampf bleiben und nur den Archäologen
dienen! "
"Puissent nos tranchées alsaciennes des Vosges
et de la plaine du Rhin rester hors des combats
sanglants et servir seulement aux
archéologues!

Robert Forrer, 15 septembre $1915^{1}$

Dès le 31 juillet 1914, le Reichsland Elsass-Lothringen (qui regroupe l'Alsace et la Moselle depuis 1871) est déclaré en état de danger de guerre (Kriegsgefahrzustand). La loi prussienne du 4 juin 1851 sur l'état de siège est instaurée, entraînant notamment une restriction des libertés individuelles et publiques ainsi qu'une subordination des autorités civiles aux autorités militaires. Le 3 août, l'Allemagne déclare la guerre à la France : l'Alsace et la Lorraine se trouvent alors en pleine zone de combats. Après une rapide guerre de mouvement, le front se fige et se stabilise dans de nombreux secteurs, notamment en Alsace. Certaines parties du front connaissent des modifications de tracé significatives, par exemple dans l'Artois et en Champagne en 1915, devant Verdun et dans la Somme en 1916, dans l'Aisne en 1917, dans la Somme, la Flandre, l'Aisne et la Marne, la région de Saint-Mihiel ainsi que l'Argonne en 1918.

Les aménagements et les travaux de fortifications menés en profondeur par les deux camps sur plusieurs dizaines de kilomètres, depuis la première ligne de front jusqu'à l'arrière, entraînent le déplacement de millions de mètres cubes de terre, sable et rocher. Des sites archéologiques sont alors découverts fortuitement et les belligérants réalisent diverses fouilles et observations. Ces opérations de «sauvetage» n'ont 
toutefois pas été menées partout dans des conditions identiques. Si les découvertes réalisées du côté français sont anecdotiques et manquent souvent de précision, les sites mis en évidence par les troupes allemandes bénéficient quelquefois d'une attention plus poussée. Tous les secteurs ne sont cependant pas concernés de la même manière. Les interventions sont généralement menées dans des zones "calmes" situées en retrait. Il faut souligner qu'en Alsace et en Moselle, la guerre se déroule sur le territoire allemand, ce qui permet aux découvertes de bénéficier des réseaux de l'administration allemande en place depuis une quarantaine d'années. Plusieurs personnalités jouent alors un rôle important: Robert Forrer (1866-1947) à Strasbourg et Johann Baptist Keune (1858-1937) à Metz². Grâce à eux, de nombreux sites sont documentés.

\section{Des aménagements militaires destructeurs}

Dans son journal de guerre, l'Alsacien Charles Spindler (1865-1938) décrit des travaux militaires intenses et le creusement d'innombrables tranchées: ils sont effectués à partir de la mobilisation selon une planification préparée en temps de paix et marquent, à partir des premiers mois du conflit, la périphérie de l'agglomération strasbourgeoise ${ }^{3}$. On fortifie à la hâte les hauteurs et certaines agglomérations sont entourées de lignes de protection et d'abris, tandis que de nombreux arbres sont sacrifiés aux nécessités de la défense. Cet artiste-écrivain constate avec tristesse les transformations :

Je ne reconnais plus le paysage : la guerre l'a transformé. Des villages qui autrefois étaient enfouis sous la verdure s'étalent maintenant sous la lumière crue comme des jouets d'enfants. On a rasé tous les arbres, la belle allée de peupliers au-dessus de Kolbsheim, les magnifiques arbres de la propriété Grunelius, tout a été sacrifié à la défense de la ville. Ils ont été remplacés par des haies de ronce armée, doubles, triples, en zigzag; le terrain est creusé de profondes tranchées d'où émergent des abris, des refuges couverts de tôle ondulée: un paysage volcanique dont le caractère est encore accentué par les inondations artificielles qui ont changé en lacs d'eau stagnante les grasses prairies de la banlieue de Strasbourg. Quant au travail souterrain, on ne peut s'en rendre compte que par les entrées des galeries qui forment des trous noirs encadrés d'un étayage de madriers ${ }^{4}$.

Les travaux de grande ampleur bouleversent profondément les sols. L'archéologue strasbourgeois Robert Forrer fait un constat identique et s'en émeut :

C'est surtout dans les premières semaines de la guerre, lorsque les troupes françaises ont progressé jusqu'à Mulhouse et ont menacé la vallée de la Bruche en Basse-Alsace, que de vastes réseaux de tranchées et autres travaux de fortifications ont sans nul doute détruit un nombre très important de sites archéologiques. Les découvertes ont été perdues, d'autres ont été dispersées ${ }^{5}$.

Les intellectuels alsaciens avaient pris largement conscience de l'impact des travaux de fortification sur le patrimoine régional. 
Figure 1

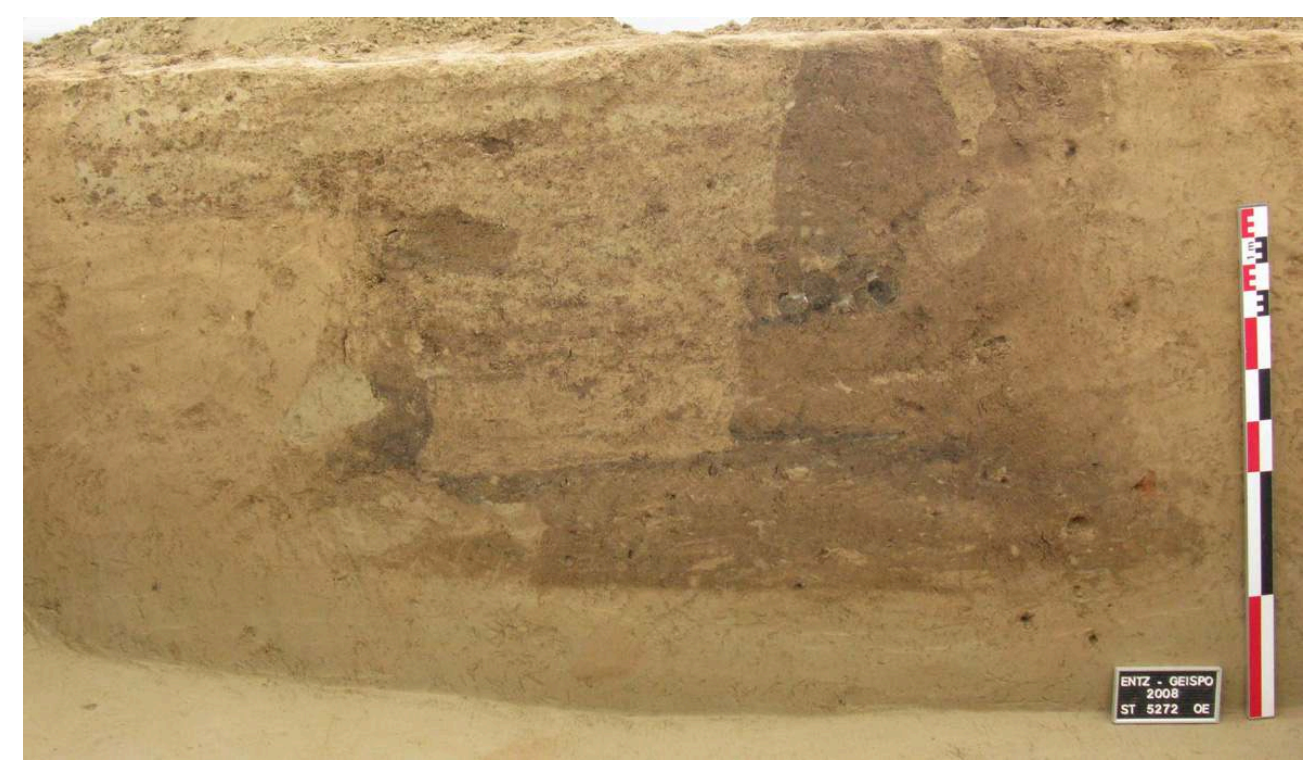

SILO LATÉNIEN RECOUPÉ PAR UNE TRANCHÉE DE LA PREMIÈRE GUERRE MONDIALE À GEISPOLSHEIM " SCHWOBENFELD " (BAS-RHIN).

PHOT. LANDOLT, M. (C) PAIR.

Le site de Geispolsheim «Schwobenfeld » (Bas-Rhin), récemment fouillé dans le cadre de l'archéologie préventive, illustre bien le phénomène de recoupement de structures observé sur ces sites. En effet, de nombreuses structures pré- et protohistoriques, antiques et médiévales ont été traversées ou détruites par des tranchées et abris implantés lors des travaux de fortification de la position de Strasbourg et la Bruche menées entre 1914 et $1916^{6}$ (fig. $\mathbf{n}^{\circ} \mathbf{1}$ ). Cette situation se retrouve sur de nombreux sites d'Alsace et de Lorraine situés dans la zone des combats. Les prospections aériennes dévoilent encore aujourd'hui cet enchevêtrement de structures. Dans la Meuse, par exemple, des réseaux de tranchées se superposent aux vestiges d'enclos, probablement protohistoriques, à Fresnes-en-Woëvre, Lacroix-sur-Meuse, Spincourt ou Marchévilleen-Woëvre et ceux d'une agglomération antique à Amel-sur-l'Étang/Senon ${ }^{7}$ (fig. $\mathbf{n}^{\circ} \mathbf{2}$ ). 
Figure 2

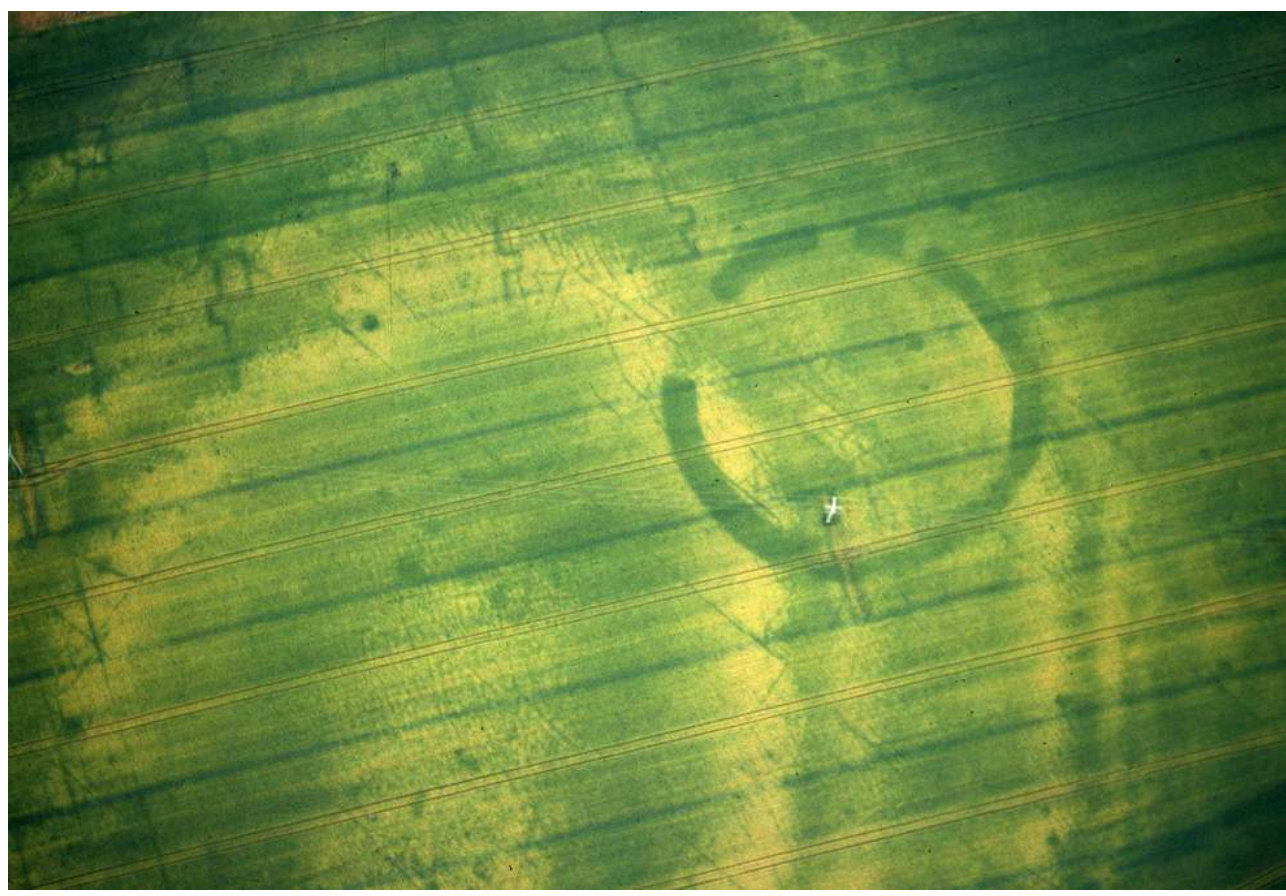

PHOTOgRAPHIE AÉRIENNE D'UN ENCLOS CIRCULAIRE VRAISEMBLABLEMENT PROTOHISTORIQUE SITUÉ À PROXIMITÉ de tRANCHÉES de LA PREMière GUERRE MONDIALE À SPINCOURT (MEUSE).

PHOT. JACQUEMOT, D., 2005. (C) SERVICE RÉgIONAL DE L'ARCHÉOLOgIE, DRAC LORRAINE.

Enfin, de nombreux cas illustrent la réutilisation de sites fortifiés par les militaires. Les sites de hauteur pré- et protohistoriques sont réinvestis car leur implantation est souvent liée à des points d'observation privilégiés ${ }^{8}$ : " qui tient les hauts tient les bas ». Les châteaux forts, abbayes et églises offrent également des lieux d'observation ou de cantonnement stratégiques, facilement dissimulables à l'ennemi ou aménageables ${ }^{9}$. Les vestiges, souvent ténus, nécessitent un œil exercé pour être reconnus et interprétés. De nombreux sites ont disparu, emportés sans même qu'on ait soupçonné leur existence par cette intense activité de creusement. À Cumières-le-Mort-Homme (Meuse) près de Verdun, il ne reste plus rien du site néolithique qui avait livré en 1873 une fosse et un silo avec inhumation multiple rendue célèbre à travers la dénomination d'" Homme de Cumières $»^{10}$ : les tristement célèbres combats de 1916-1917 ont anéanti ses vestiges. En Argonne, les sites de production de céramique antique et les nécropoles protohistoriques ont été bouleversés par les violents combats et les importantes excavations militaires ${ }^{11}$.

\section{Des prises en compte différentes selon les belligérants}

Une conférence tenue le 29 juin 1916 par le Dr Hans Lehner (1865-1938), directeur du musée de Bonn (Allemagne, Rhénanie-du-Nord-Westphalie), sur les découvertes d'objets archéologiques sur le front ouest, est emblématique de la position généralement adoptée dans les milieux universitaires et intellectuels allemands : s'il déplore que la guerre ait interrompu les relations scientifiques avec les chercheurs français et belges, il souligne aussi avec une certaine fierté l'intérêt manifesté par les 
officiers et les soldats allemands pour l'environnement archéologique de leur secteur de cantonnement ${ }^{12}$. Il en veut pour preuve les nombreuses demandes d'informations sur les découvertes qui lui ont été adressées, y compris par des soldats qu'il ne connaît absolument pas, à l'occasion des découvertes réalisées lors de travaux de fortification, notamment au cours du creusement de tranchées et de l'aménagement d'abris. L'un de ces informateurs les plus actifs est, précise-t-il, un officier séjournant dans la région de Reims (Marne), qui lui signale la découverte d'une hache polie dans le secteur de Vouziers (Ardennes) et les fouilles de fosses laténiennes, qui font l'objet d'une publication en 1916 dans un journal militaire du VIII. Reservekorps ${ }^{13}$. Le Dr H. Lehner ne manque pas non plus de saluer la découverte d'un remarquable autel dédié à Hercule Saxetanus près de Metz, dont il décrit et analyse longuement l'inscription ${ }^{14}$.

La prise de conscience de l'ampleur des dommages portés au patrimoine archéologique par le conflit est également à mettre au crédit du Dr Hans Lehner ${ }^{15}$. Devant la multiplication des signalements qui parviennent aux sociétés archéologiques allemandes, dont les membres font remonter les informations collectées sur le front, et afin d'éviter la dispersion de toutes ces découvertes, il conclut en proposant d'instaurer un organisme central de collecte. Il ajoute que cette mission pourrait être confiée à une institution qui a fait ses preuves : la Römisch-Germanische Kommission de Francfort-surle-Main (Allemagne, Hesse). À cet effet, pour répondre aux nécessités de la " Kriegsarchäologie ", un petit groupe de scientifiques se fédère au sein de la RGK, parmi lesquels on recense les noms de Gerhard Bersu (1889-1964), Hans Dragendorff (1870-1941), Friedrich Drexel (1885-1930), Ernst Fabricius (1857-1942), Heinrich Jacobi (1866-1946), Karl Schumacher (1860-1934), Wilhelm Unverzagt (1892-1971), etc.

\section{Du côté français : un suivi ponctuel des découvertes}

Force est de constater que les travaux français n'ont consisté, comme c'était alors la tradition, qu'à recueillir simplement du mobilier destiné à alimenter essentiellement des collections privées. Quelques contre-exemples existent cependant lors de l'édification d'ouvrages militaires défensifs, mais ils datent d'avant-guerre. Tel est le cas de la découverte de la nécropole mérovingienne de Vaux (Meuse), mise au jour en 1882, lors des travaux de construction du fort éponyme. Le mobilier découvert déposé au musée de Verdun avait pu être étudié par Félix Liénard (1812-1894) ${ }^{16}$.

$\mathrm{Au}$ cours du conflit, il ne semble pas que la conduite à tenir en cas de découverte archéologique ait donné lieu à la diffusion de directives de la part des états-majors alliés. Le droit français, reposant alors d'une part sur la loi du 31 décembre 1913 concernant la protection des Monuments historiques et, d'autre part, sur l'article 716 du Code civil relatif aux découvertes de trésors, n'a laissé que peu de place à une gestion organisée. La priorité a été donnée à la mise en sécurité des monuments et des collections des musées menacés par les combats. En outre, les découvertes archéologiques effectuées par l'armée française ont souvent été considérées comme des faits d'une importance limitée. Elles n'ont généralement été relayées que dans les journaux publiés à destination d'un lectorat de mobilisés ${ }^{17}$. Quelques exemples s'en démarquent cependant en Île-de-France, en Champagne et dans le nord de la France. Régulièrement, les archéologues et préhistoriens mobilisés ou présents à proximité du front signalent des découvertes dans des publications de sociétés archéologiques, notamment dans le Bulletin de la Société Préhistorique Française : Louis Barot (1873-1951) ${ }^{18}$, 
Jules Bossavy (1863-1936) ${ }^{19}$, Victor Commont (1866-1918) ${ }^{20}$, Georges Courty $(1875-1953)^{21}$, Léon Coutil (1856-1943) ${ }^{22}$, Marcel Hémery (1892-1958) ${ }^{23}$, Philippe Reynier $^{24}$, Paul Trassagnac ${ }^{25}$, etc. Même s'il s'agit généralement d'informations collectées auprès des militaires et d'objets recueillis hors contexte, certaines interventions sont menées sur le terrain malgré la proximité des lignes ennemies occasionnant souvent des difficultés ${ }^{26}$. Ces correspondants s'inquiètent du désintérêt de certains officiers, de l'absence d'information sur les découvertes et du sort malheureux réservé aux trouvailles, parfois abandonnées sur le bord de la tranchée. Les difficultés avec l'armée sont souvent évoquées, mais les expériences ne sont pas toutes identiques $^{27}$. Certaines précisions concernant la localisation des découvertes ne peuvent pas être publiées pour des raisons de secret militaire. La mission aux armées du préhistorien et spéléologue Armand Viré (1869-1951), menée en Artois au cours de l'année 1915, reste un phénomène ponctuel ${ }^{28}$. L'écrivain-soldat français Henri Barbusse (1873-1935) décrira même la découverte d'une hache polie néolithique lors de travaux d'entretien dans une tranchée dans son roman autobiographique.

J'ai trouvé ça en creusant la terre, cette nuit, au bout du Boyau Neuf, quand on a changé les caillebottis pourris. Ça m'a plu tout de suite, c't'affutiau. C'est une hache ancien modèle. Pour un modèle ancien, c'en est un : une pierre pointue emmanchée dans un os bruni. Ça m'a tout l'air d'un outil préhistorique ${ }^{29}$.

Il est intéressant de noter qu'à la même période, l'archéologie n'est pas absente non plus sur le front oriental ${ }^{30}$. Les recherches menées dans les Dardanelles et en Macédoine par des officiers français - souvent des spécialistes d'archéologie antique dans le civil -, avec le soutien de l'état-major du corps expéditionnaire puis de l'armée d'Orient, aboutissent dès 1915 à la création du Service archéologique de l'armée d'Orient. Si les observations sont faites à l'occasion de travaux militaires comme sur le front occidental, elles sont destinées aussi à démontrer que les troupes françaises basées en Grèce respectent le patrimoine et la culture de ce pays allié. Les fouilles, menées avec une grande rigueur scientifique et qui ont fait l'objet de publications de qualité malgré les impératifs du conflit, ont ainsi permis de sauver de nombreux vestiges antiques en particulier dans la région de Salonique.

\section{Le « dépôt monétaire » exhumé entre Étain et Fresnes-en-Woëvre} (1914)

Pour le chercheur actuel, les renseignements sont peu nombreux et il est souvent difficile de déterminer avec précision l'emplacement des sites, tant les localisations sont approximatives ou données par lieux de stationnement des troupes. Le dépouillement croisé des archives militaires permet parfois d'affiner ces localisations. Sur le front de la Woëvre en Meuse, il est attesté, par exemple, qu'un « dépôt monétaire » dans " un pot de terre grise, muni de deux anses, enfouis à $1 \mathrm{~m} 50$ de profondeur » a été exhumé entre Étain et Fresnes-en-Woëvre (Meuse) ${ }^{31}$, ce qui reste très imprécis. La découverte a été réalisée par des soldats de la défense mobile de Verdun le 16 décembre 1914. L'identification de monnaies et jetons antiques, médiévaux et modernes, pose problème ${ }^{32}$. 


\section{Le four gallo-romain de Vauquois (1915)}

En Argonne, la butte de Vauquois (Meuse), dont la topographie a profondément été modifiée à travers d'énormes entonnoirs liés à la guerre des mines, est au centre d'un important groupe d'officines de production de céramique daté de la fin de l'Antiquité (Avocourt « Forêt de Hesse », Vauquois, «Les Allieux », « Pont des Quatre Enfants »...). La fouille en 1915 d'un atelier de potier antique aux "Allieux», situé au sud-est du village, mérite d'être mentionnée ${ }^{33}$. Cette découverte est liée à la construction d'un poste de commandement à l'emplacement d'un dépôt du génie pour l'état-major de la $19^{\mathrm{e}}$ brigade, commandée par le colonel Henri Pinoteau (1861-1936) ${ }^{34}$. La fouille réalisée entre le 20 et le 26 avril 1915, par le capitaine Provost et Louis Gain (1883-1963), naturaliste et climatologue au Muséum National d'Histoire Naturelle alors officier porte-drapeau au $46^{\mathrm{e}}$ régiment d'infanterie ${ }^{35}$, a permis de dégager un four à céramique engobée et une fosse dépotoir datés entre la fin du $\mathrm{II}^{\mathrm{e}}$ et le début du $\mathrm{III}^{\mathrm{e}}$ siècle. Les vestiges, retrouvés à $40 \mathrm{~cm}$ sous la surface du sol, ont livré de nombreux fragments de céramique ainsi que des supports de cuisson. Il est intéressant de souligner que Louis Gain avait fait conserver le four intact à l'intérieur de l'abri en consolidant son assise. La visite du lieutenant-colonel Raymond Donau (1862-1930), commandant du $240^{\mathrm{e}}$ régiment d'infanterie ( $149^{\mathrm{e}}$ brigade) tenant un secteur voisin, le "Bois de Cheppy", jusqu'au 26 avril 1915, mérite d'être mentionnée. Ce dernier avait exploré le Sud tunisien et effectué des fouilles archéologiques avant le conflit. Malgré des consignes sur la suite des travaux et la protection du four, le départ en permission de L. Gain le 26 avril, et la relève de la position par la $20^{\mathrm{e}}$ brigade du général Louis-Elisée Bassenne (1858-1938), entraîne la destruction des vestiges. Ainsi, en revenant sur les lieux le 6 mai, L. Gain n'a pu que constater l'effondrement du four suite à la sape de ses fondations ${ }^{36}$. Cependant, le Dr. Francis Guilbert (1889-1959) de Cholet (Maine-et-Loire), membre de la Société Préhistorique Française à partir de 1924, qui avait également séjourné dans le secteur vraisemblablement avec le $76^{\mathrm{e}}$ régiment d'infanterie, avait réalisé quelques observations complémentaires notamment un schéma qui fut très utile pour les travaux ultérieurs de Georges Chenet (1881-1951) ${ }^{37}$. Après la guerre, Louis Gain transmet même une photo du four de Vauquois à l'archéologue qui parcourt les secteurs d'Argonne malmenés par les combats à la recherche des sites qu'il avait fouillé avant le conflit ${ }^{38}$. L'archéologue retrouve l'abri de commandement, complètement effondré et inondé, dans un secteur très malmené par les combats. Il réalise des fouilles dans le secteur grâce aux informations obtenues de l'ingénieur Guy Gaudron (1891-1965), qui avait rencontré Louis Gain, et du Dr. Francis Guilbert ${ }^{39}$. Ce dernier avait, par ailleurs, découvert de la céramique antique dans plusieurs secteurs d'Argonne pendant la guerre ${ }^{40}$. D'autres sources mentionnent des découvertes aux "Allieux ». On note par exemple celles du capitaine Lambert en service dans un étatmajor, ami de l'archéologue Émile Espérandieu (1857-1939), qui indique la découverte de grandes quantités de tuiles romaines lors du creusement de tranchées dans la forêt à proximité du four précédemment décrit ${ }^{41}$.

\section{Les vestiges gallo-romains d'Aubréville}

Après le conflit, Georges Chenet ne peut que déplorer la destruction de nombreux sites comme à Aubréville « Haut-Mulard» (Meuse) où l'implantation d'un abri avait détruit une fosse qui avait livré un important corpus de gobelets en juillet 1914 (à environ 
$1,5 \mathrm{~km}$ de celui découvert à Vauquois en 1915$)^{42}$. La découverte de murs antiques, en petit appareil recouvert d'enduit peint, est cependant mentionnée pendant la guerre sur la même commune aux "Champs-Collas ", lors de l'ouverture d'une carrière par le Génie. Dans l'après-guerre, G. Chenet réalise des recherches complémentaires qui lui permettent de confirmer la présence d'un établissement rural gallo-romain ${ }^{43}$. Cet inventaire dévoile ainsi une carence flagrante d'informations. Pourtant, lorsque l'on observe l'étendue de la zone de front, et que l'on compare cette dernière à la carte des sites connus avant 1914, il apparaît que certains d'entre eux ont vraisemblablement fait l'objet de découvertes fortuites et/ou ont été détruits.

\section{Les intellectuels nancéens}

Les proches milieux intellectuels nancéiens quant à eux ne semblent avoir joué aucun rôle dans l'étude des vestiges menacés de destruction par les combats. Parmi ses figures, Georges Goury (1875-1959), conservateur du Musée lorrain de Nancy depuis 1908, ne participe pas à la guerre et quitte rapidement la Lorraine pour s'exiler en Ardèche, puis dans la Drôme où il s'intéresse à des sites bien éloignés du front ${ }^{44}$. Dans sa propriété de Saint-Hilairemont à Courtémont (Marne) près de Sainte-Menehould, l'archéologue fait enterrer une partie de sa collection archéologique. Celle-ci fut partiellement détruite et fit l'objet de dommages de guerre.

\section{Du côté allemand : le rôle déterminant des responsables des musées}

Face à ce constat, on ne peut qu'être frappé par l'abondance et la qualité de la documentation produite par l'armée allemande, bien que cette situation soit souvent le fruit d'initiatives individuelles au sein de l'encadrement. Elle résulte toutefois d'une attitude plus ou moins coordonnée du commandement à tous les niveaux, découlant d'une politique mise en place dans les zones de combats, en vue de sauvegarder le patrimoine artistique (Kunstschutz) menacé par les hostilités.

Les « atrocités culturelles » du début de la guerre, notamment l'incendie qui a ravagé la bibliothèque de l'université de Louvain (Belgique) et le bombardement de la cathédrale de Reims (Marne) ${ }^{45}$ ont amené les autorités politiques et militaires allemandes à dépasser les préconisations générales des conventions de La Haye (1899 et 1907). De cette politique en faveur du patrimoine artistique, aux intentions pas toujours claires, ont découlé des décisions, des nominations de responsables et des actions de sauvetage dont l'aire s'est étendue aux départements français occupés, à la Belgique et même à la zone méridionale de la Lorraine annexée (entre Metz et Vosges). Toutefois, dans le cadre du Kunstschutz, les activités de sauvegarde ont été utilisées à diverses reprises comme vecteurs d'une propagande devenue un instrument de la "guerre totale».

D'importantes fouilles sont menées à différents endroits du front ouest, par exemple sur l'agglomération antique de Bavay (Nord), la nécropole laténienne de Bucy-le-Long (Aisne) ou le site antique de Carignan (Ardennes) ${ }^{46}$. Ces fouilles, parfois méthodiques, démontrent bien souvent l'avance méthodologique de l'archéologie allemande du début du XXe siècle.

En Alsace et en Moselle, l'archéologie bénéficie de surcroit pendant la guerre de la structuration ancienne des musées, en particulier ceux de Metz et de Strasbourg, qui 
centralisent les découvertes avec le soutien des autorités, dans le cadre de puissantes sociétés d'histoire et d'archéologie telles la Société pour la Conservation des Monuments Historiques d'Alsace (Gesellschaft zur Erhaltung der geschichtlichen Denkmäler im Elsass) fondée en 1855, ou la Société d'Histoire et d'Archéologie de Lorraine (Gesellschaft für lothringische Geschichte und Altertumskunde) fondée en 1888. Les responsables de ces musées ont ainsi la possibilité d'intervenir à proximité du front. Johann Baptist Keune, en Lorraine, et Robert Forrer, en Alsace, jouent un rôle éminent dans le suivi archéologique des découvertes. Certains chercheurs préfèrent quant à eux quitter la région : Karl Sebastian Gutmann (1854-1931) s'installe ainsi dès le début de la guerre ${ }^{47}$ dans sa région d'origine, à Breisach-am-Rhein (Allemagne, Bade-Wurtemberg). Les aménagements menés par les troupes allemandes sur les sites fortifiés hallstattiens dans le Sundgau - Kœstlach-Mœrnach « Kastelberg » et Illfurth «Britzgyberg 》 (HautRhin) - qu'il avait fouillés, ne font pas l'objet d'un suivi de sa part. Il documente cependant des découvertes réalisées à proximité de son nouveau lieu de résidence lors des travaux de fortification de la position de Neuf-Brisach/Breisach-am-Rhein. Ainsi, il fouille en juin 1916, à Hochstetten (Allemagne, Bade-Wurtemberg), trois fosses laténiennes mises au jour lors du creusement de tranchées en août $1914^{48}$.

\section{Robert Forrer en Alsace}

En Alsace, Robert Forrer, conservateur du Musée préhistorique et gallo-romain de Strasbourg depuis 1909, s'intéresse de près, et cela dès l'automne 1914, aux trouvailles archéologiques réalisées lors de l'installation de la position fortifiée de Strasbourg, mais aussi dans d'autres secteurs du Bas-Rhin ${ }^{49}$ (fig. $\mathbf{n}^{\circ} \mathbf{3}$ ). Il déplore sans ambages les nombreuses et aveugles destructions (en particulier au moment de l'avancée des troupes françaises dans le sud de l'Alsace, dans les premières semaines de la guerre), ainsi que la dispersion des objets exhumés; il rappelle au commandement que celui-ci doit informer les troupes de la nécessité de signaler toute découverte. L'archéologue strasbourgeois est l'une des personnalités marquantes de la vie culturelle de l'Alsace du Reichsland et ses recherches sont connues bien au-delà des frontières régionales et jusqu'à Berlin. L'empereur Guillaume II, féru d'archéologie, s'intéresse personnellement à ses travaux et ne manque jamais, lors de ses visites annuelles en Alsace, de visiter les chantiers en cours ou de découvrir les nouvelles acquisitions du musée. R. Forrer est également l'un des membres les plus en vue du Hohkönigsburgverein (association du Haut-Koenigsbourg) : il a présidé à l'aménagement et à la décoration intérieure du Haut-Koenigsbourg lors des travaux de restauration et de reconstruction réalisés par l'architecte Bodo Ebhardt (1865-1945), pour ce château offert aux Hohenzollern par la Ville de Sélestat. R. Forrer peut ainsi bénéficier d'une excellente introduction auprès des autorités civiles et militaires, d'autant plus que sa nationalité suisse lui confère une certaine neutralité dans le conflit. C'est donc avec bienveillance qu'est accueillie sa demande d'accès aux sites où des vestiges archéologiques ont été mis au jour lors de travaux militaires, et le haut-commandement lui accorde aisément un laissez-passer pour visiter les chantiers et collecter des informations sur les

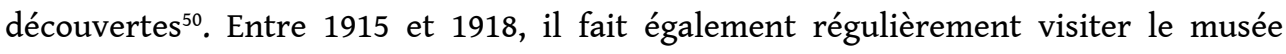
archéologique de Strasbourg à des groupes de soldats blessés ${ }^{51}$. 
Figure 3

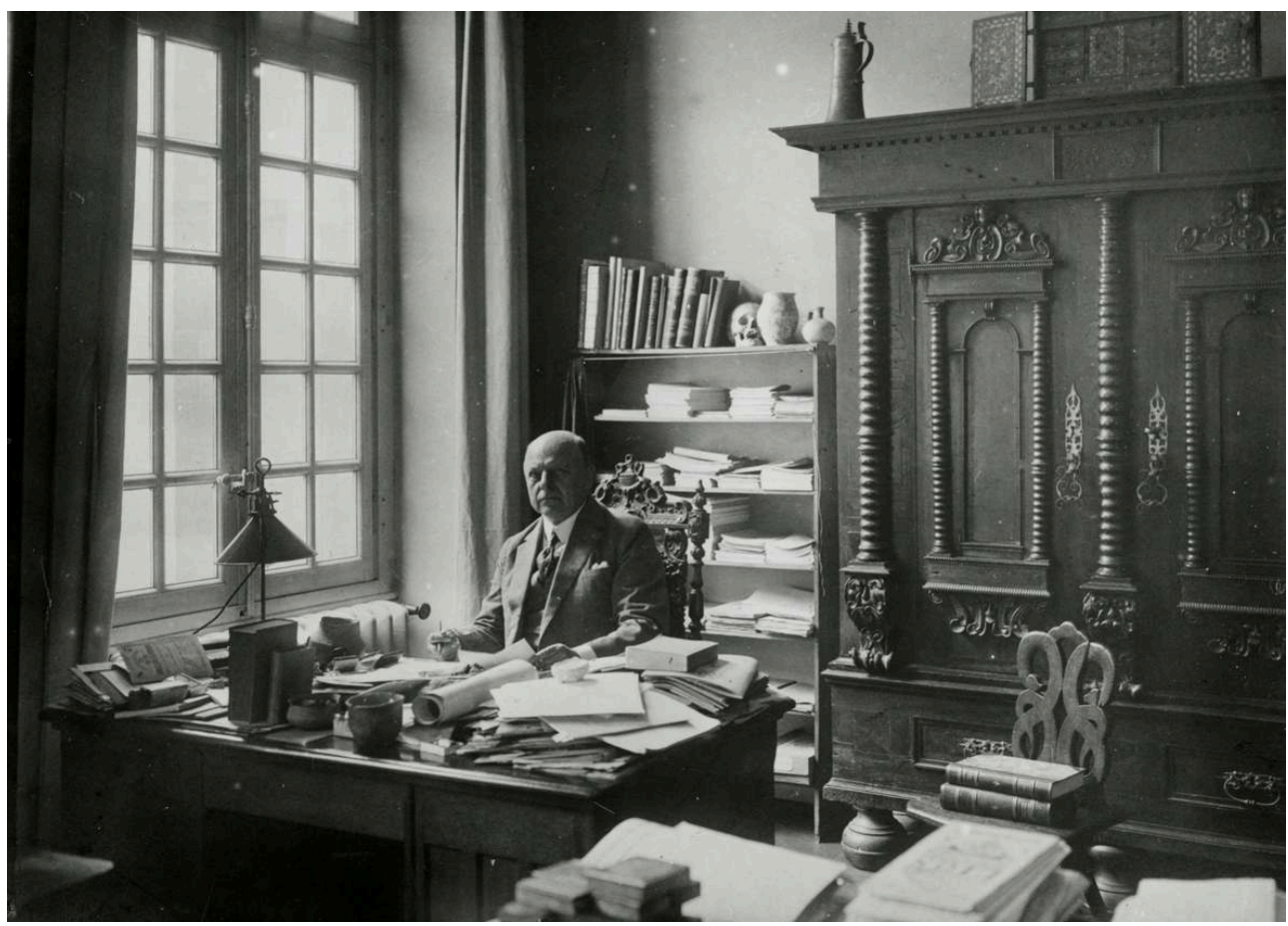

ROBERT FORRER (1866-1947) DANS SON BUREAU DU MUSÉE ARCHÉOLOgIQUE DE STRASBOURg (BASRHIN) EN 1917.

(C) MUSÉE ARCHÉologiQue DE StRASBOURg.

La notoriété de R. Forrer dépassant largement le cadre strictement alsacien, une découverte faite entre Sand et Appenweier (Allemagne, Bade-Wurtemberg) par un soldat qui installait des poteaux télégraphiques lui est également signalée : il s'agit d'un trésor monétaire, initialement d'une centaine de pièces, que les soldats se sont partagées et dont vingt-et-une ont été transmises à $\mathrm{R}$. Forrer. La similitude des pièces milite en faveur d'un trésor monétaire enfoui vers le milieu du III $^{\mathrm{e}}$ siècle, à la suite d'une incursion des Alamans ${ }^{52}$. D'autres découvertes sont également signalées, en particulier celles de céramique sigillée à décor à la molette dans le secteur d'Avocourt (Meuse) par le colonel Walther au cours de l'été $1915^{53}$. L'officier allemand correspond avec R. Forrer, qui avait fouillé de l'atelier de sigillée de Dinsheim-sur-Bruche «Heiligenberg » (Bas-Rhin) en 1909-1910, pour lui demander conseil et l'aider à identifier ses trouvailles ${ }^{54}$. Il en est de même pour des céramiques romaines mises au jour à Écourt-Saint-Quentin (Pas-de-Calais) au sud d'Arras en août 1917, à proximité de la ligne Hindenburg55. Le lieutenant Wegener, domicilié à Strasbourg, fait don du mobilier au musée archéologique de Strasbourg ${ }^{56}$.

\section{Johann Baptist Keune en Lorraine}

Originaire de Trèves (Allemagne, Rhénanie-Palatinat), Johann Baptist Keune étudie l'antiquité à Marburg, Bonn et Vienne où il devient l'assistant de l'archéologue Otto Berndorf (1838-1907), avant de retourner dans sa ville natale où il enseigne à partir de 1889 et collabore avec le musée local ${ }^{57}$. En 1892, il s'installe à Montigny-lès-Metz (Moselle) pour occuper le poste de professeur de latin dans le lycée diocésain (petit séminaire). En 1896, tout en continuant d'enseigner, il prend en charge le musée 


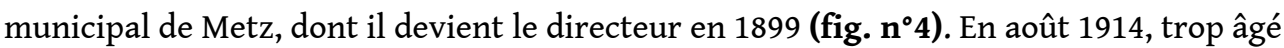
pour être mobilisé, il continue à se consacrer à la direction du musée. À partir de décembre, il assume de surcroît la responsabilité du Service de protection des œuvres d'art et des biens culturels (Schutzerwahrung von Kunst und Kultuwerken) ${ }^{58}$.

Figure 4

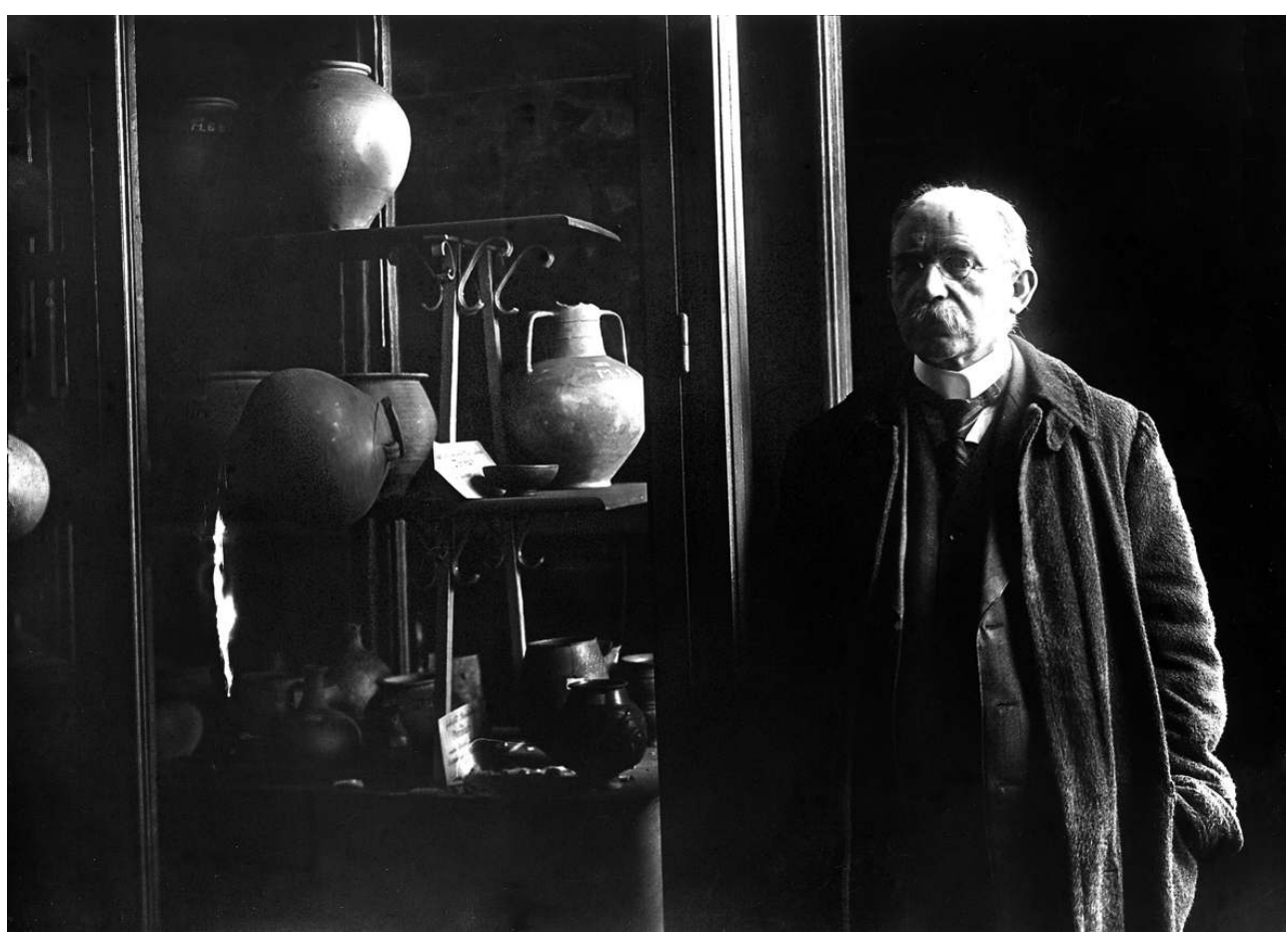

JOHANN BAPTIST KEUNE (1858-1937) DEVANT UNE VITRINE DU MUSÉE DE METZ (MOSELLE) APRÈS LE BOMBARDEMENT AÉRIEN DU 19 DÉCEMBRE 1915.

(c) MUSÉE DE LA COUR D'OR-METZ MÉTROPOLE, KM 356.

Il est alors chargé par le commandement de la région fortifiée de Metz de la préservation $d u$ patrimoine menacé par la guerre. Cette mission relevant du Kunstschutz l'a amené à veiller sur un vaste territoire dans l'arrière-front allemand, s'étendant de Montmédy (Meuse) à Marsal/Vic-sur-Seille (Moselle). J. B. Keune s'est ainsi appliqué à organiser des recherches, gérer les découvertes fortuites et faire protéger des œuvres d'art menacées mais intransportables (la mise au tombeau de Ligier Richier à Saint-Mihiel par exemple). Lorsque les circonstances le permettaient, il a fait procéder au transfert de ces œuvres dans divers lieux à Metz. Tel a été le cas de l'autel d'Hercule Saxetanus découvert à Norroy-lès-Pont-à-Mousson (Meurthe-etMoselle) en décembre 1915 ou au début de $1916^{59}$.

Cette activité de sauvetage et une partie des œuvres préservées sont évoquées dans un opuscule rédigé par J. B. Keune ${ }^{60}$. Pour examiner ce patrimoine, il effectue des tournées dans l'arrière-front, réalisant des photographies dont l'essentiel constitue un remarquable fonds documentaire de près de mille plaques de verre. Volontairement ou pris dans l'engrenage de ses fonctions, il participe à diverses actions de propagande, dont la plus importante est l'Exposition de guerre (Kriegs-Ausstellung) à Metz en 1917. C'est ainsi qu'il est amené, à travers certaines publications, à prétendre que les «barbares iconoclastes » détruisant les monuments et les œuvres d'art ne sont pas les 
Allemands, mais les Français, en écho à la propagande française qui accuse les autorités allemandes des mêmes actions destructrices ${ }^{61}$.

Sur l'arrière-front de la $5^{\mathrm{e}}$ armée travaillaient aussi deux homologues de Johann Baptist Keune: l'historien d'art Ludwig Burchard (1886-1960) qui occupait les fonctions d'expert du patrimoine artistique auprès du commandement de la région fortifiée de Metz, et Heribert Reiners (1880-1960), professeur d'histoire de l'art et d'archéologie mobilisé avec le grade de sous-lieutenant, qui était affecté à l'inspection des étapes ${ }^{62}$. On lui attribue le sauvetage de la statue de Jules Bastien-Lepage, œuvre de Rodin, retirée du cimetière de Damvillers (Meuse) et transférée à Metz.

\section{Les découvertes archéologiques réalisées du côté allemand au cours du conflit}

\section{Les sites mis au jour en Alsace}

L'inventaire des découvertes réalisées en Alsace pendant la Grande Guerre couvre un large champ chronologique, du Paléolithique au Moyen Âge, avec une multitude de petites observations ou «sauvetages" liés à des circonstances diverses. R. Forrer multiplie les interventions ou, s'il arrive trop tard, essaie de collecter informations et mobilier auprès des soldats. La plupart des découvertes concerne des sépultures, car les ossements humains sont bien plus faciles à repérer par les terrassiers que des fosses d'habitat, perceptibles parfois uniquement par une terre plus foncée et quelques tessons épars.

\section{Plusieurs millénaires d'histoire à travers les sites de la position fortifiée de Strasbourg et de la Bruche (1914-1916)}

Les découvertes réalisées autour de la position fortifiée de Strasbourg sont nombreuses: Blaesheim en 1917, Ergersheim en 1914, Hangenbieten en 1914-1915, Holtzheim en 1914-1915, Kolbsheim en 1914, Mittelhausbergen en 1915, Oberschaeffolsheim en 1914 et 1915, Scharrachbergheim-Irmstett en 1915 et 1917, Wolfisheim en 1914 et Wolxheim en $1914^{63}$ (fig. n5). Ces découvertes ont fait l'objet d'une documentation plus ou moins précise dans les carnets d'inventaires du musée archéologique de Strasbourg (notes, croquis, plans, courriers, articles de presse, etc.). Leurs localisations ont pu être précisées, voire corrigées, notamment grâce à l'étude monographique récente de la position fortifiée de Strasbourg ${ }^{64}$, et les quelques erreurs de localisation sont à mettre sur le compte de la précipitation entourant les interventions. 


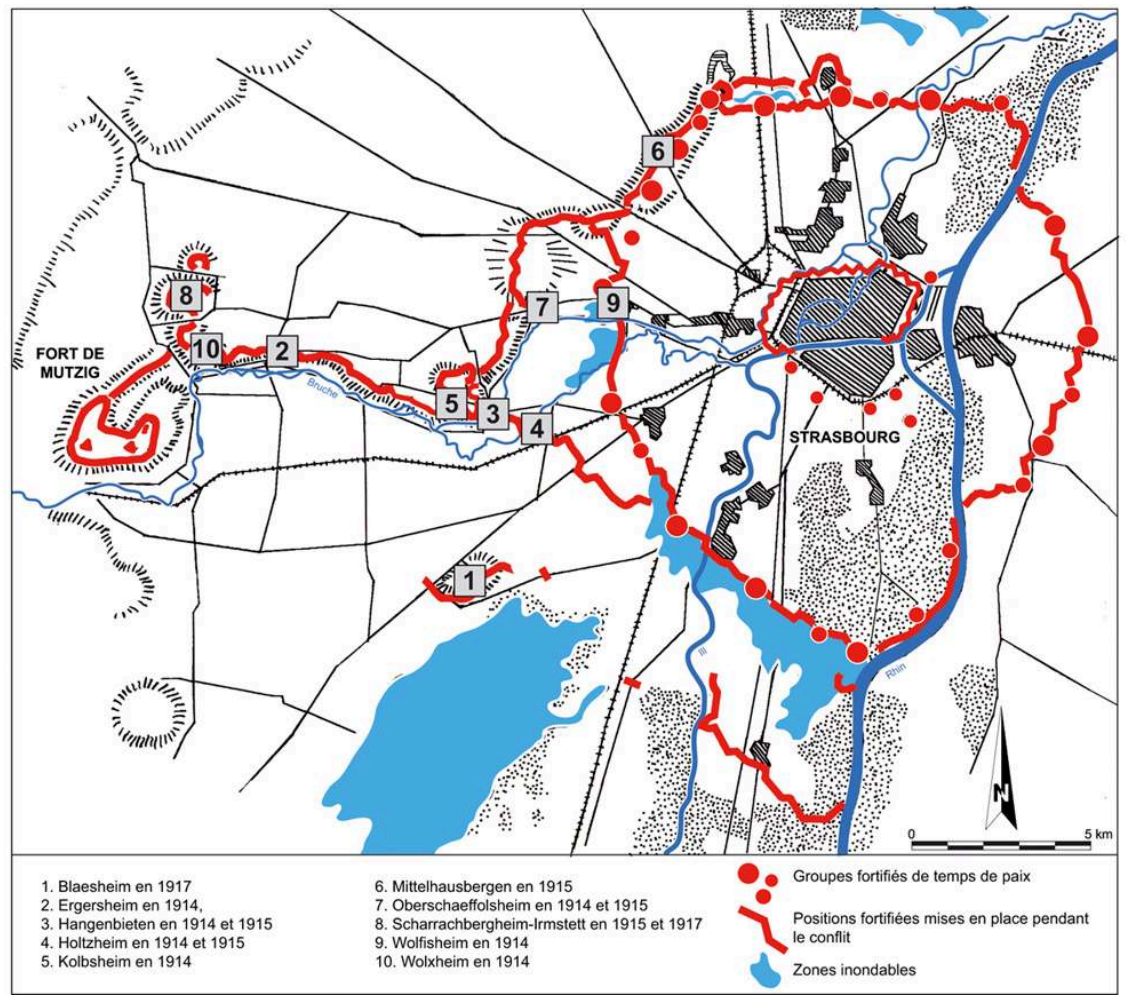

DÉCOUVERTES ARCHÉologiques MENTIONNÉES LORS DES tRAVAUX DE MISE EN PLACE ET D'ENTRETIEN DE LA POSITION FORTIFIÉE DE STRASBOURg ET DE LA BRUCHE (BAS-RHIN).

DOCUMENT : LANDOLT, M., D'APRÈS PH. BURTSCHER, MODIfIÉ. (C) PAIR.

À Mittelhausbergen «Alterberg " (Bas-Rhin), un niveau riche en fragments de charbon de bois, objets lithiques et ossements a pu être observé en 1915 à environ 2,50/3 m de profondeur dans du lœss vierge lors de l'installation de batteries d'artillerie, dans des emplacements creusés sur la pente sud-est de la crête ${ }^{65}$. Ces aménagements étaient destinés à abriter des obusiers de $210 \mathrm{~mm}$, au niveau du point d'appui du "Nellkopf ", particulièrement élaboré, à proximité de la Feste von Baden (aujourd'hui fort Frère) ${ }^{66}$. Parmi le mobilier, un grattoir probablement moustérien en silex a pu être récupéré par R. Forrer.

Les découvertes concernant le Néolithique sont nombreuses. Pour le Néolithique ancien, quelques fosses ont été fouillées à Oberschaeffolsheim (Bas-Rhin) à l'est de la "Lœssière Schaefer $"^{67}$, au niveau d'un point d'appui proche de la route menant à Strasbourg ${ }^{68}$. La découverte de trois sépultures en septembre 1914 est mentionnée au "Rebberg $~^{69}$, aujourd'hui appelé "Stimmelsberg ", lors du creusement de tranchées liées à la défense de la crête mise en œuvre dès $1911^{70}$. Une grande partie des objets et ossements a été perdue ou dispersée avant l'arrivée de R. Forrer, mais ce dernier réussit cependant à documenter le profil d'une sépulture et à récupérer quelques ossements, de la céramique et du mobilier lithique en pierre polie ${ }^{71}$. Le mobilier céramique peut être rattaché au Néolithique récent. À Kolbsheim (Bas-Rhin), une sépulture en décubitus dorsal du Néolithique moyen (Grossgartach) a été mise au jour lors du creusement de tranchées en janvier 1915 ${ }^{72}$. L'inhumation en position repliée, retrouvée en novembre 1914 dans le silo d'Ergersheim (Bas-Rhin), pourrait être attribuée au Néolithique récent, voire à la Protohistoire ${ }^{73}$. Les observations se sont 
limitées à la récupération de quelques tessons non décorés au niveau de la paroi de la tranchée ${ }^{74}$. Cette découverte peut être mise en relation avec les travaux de la position fortifiée de la Bruche au nord du village ${ }^{75}$. Une autre inhumation en silo, susceptible d'être attribuée à cette période, a été retrouvée sur la pente sud-ouest du «Scharrach » en 1917 à Scharrachbergheim-Irmstett (Bas-Rhin) ${ }^{76}$. La découverte d'un outil en pierre polie à proximité vient confirmer l'hypothèse d'une fréquentation néolithique ${ }^{77}$. Un autre, en silex, trouvé dans une tranchée entre Hangenbieten et Holtzheim lors de travaux de fortification, est entré dans les collections du musée archéologique de Strasbourg en $1915^{78}$. La fosse néolithique mentionnée en 1916 à Dahlenheim (Bas-Rhin) est sans rapport avec des aménagements directement militaires, mais est liée à l'exploitation de la gravière, sans doute pour fournir des matériaux entrant dans la composition du béton ${ }^{79}$. Il en est probablement de même pour les silos découverts en août 1914 à Hangebieten (Bas-Rhin) ${ }^{80}$.

Plus curieux est le contexte de la découverte d'une sépulture vraisemblablement féminine à Walbach (Haut-Rhin) dans la vallée de Munster, en décembre 1914, liée tout d'abord à un fait divers tragique... Mais la position repliée de la défunte permet à $\mathrm{R}$. Forrer d'identifier d'après un article de presse, non pas la malheureuse victime d'un meurtre, mais une authentique sépulture néolithique ${ }^{81}$. La même erreur d'interprétation est signalée à Katzenthal (Haut-Rhin) avant la guerre et pour les sépultures précédemment décrites d'Oberschaeffolsheim.

Figure 6

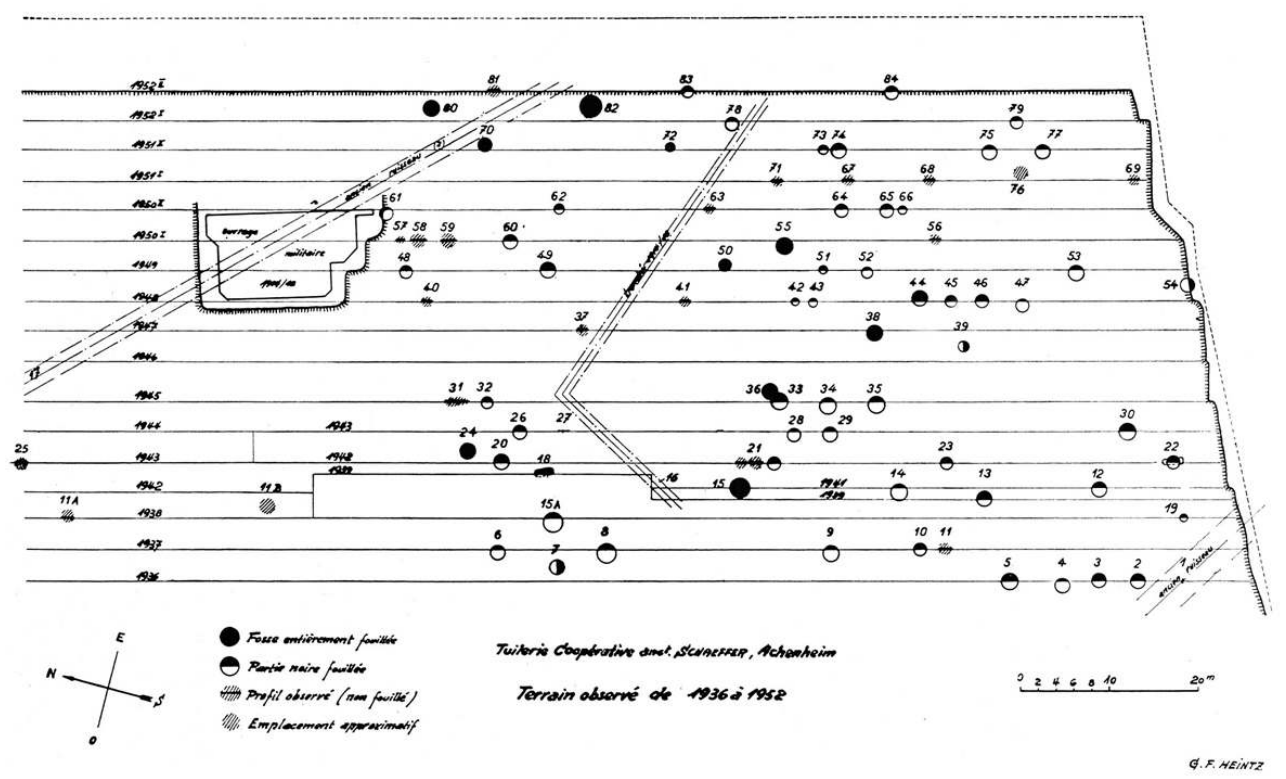

PLAN DES FOUILLES de GEORgES-FRÉdÉRIC HEINTZ À OBERSCHAEFFOLSHEIM « LœSSIÈRE SCHAEFFER » (BAS-RHIN) ENTRE 1936 ET 1952 AVEC LOCALISATION D'UNE TRANCHÉE ET DE L'ABRI BÉTONNÉ D'INFANTERIE (DANS HEINTZ, GEORgES-FRÉDÉRIC. " OBSERVATIONS ARCHÉOLOgIQUES À ACHENHEIM-BAS de 1936 À 1952 ». CAHIERS ALSACIENS d'HISTOIRE ET d'ARCHÉOLOgIE, 1953, N¹33, P. 53-66).

Pour la Protohistoire, les découvertes concernent des sites d'habitat et funéraires. Au niveau de celui d'Oberschaeffolsheim "Lœssière Schaeffer» dont les découvertes néolithiques ont déjà été présentées, un probable silo de l'âge du Fer (sans mobilier) a été fouillé en 1914 par des soldats sous la conduite de R. Forrer ${ }^{82}$. En 1915, de nouvelles fosses, probablement des silos, ont permis l'exhumation de mobilier protohistorique. 
L'extension de l'exploitation a fait l'objet d'un suivi entre 1936 et 1963 sous la conduite de Georges-Frédéric Heintz (1907-2005), mais la localisation des découvertes de R. Forrer n'a pas pu être réalisée avec certitude ${ }^{83}$ (fig. $\mathbf{n}^{\circ} \mathbf{6}$ ). Au nord-ouest de la commune de Hangenbieten (Bas-Rhin), des ouvriers occupés à des travaux de fortification sur le sommet d'une colline, à la fin d'août 1914, ont découvert deux bracelets hallstattiens en alliage cuivreux à tampons et décor gravé ${ }^{84}$ (fig. $\mathbf{n}^{\circ} 7$ ).

Figure 7

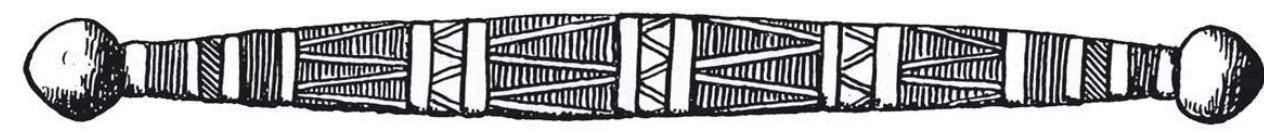

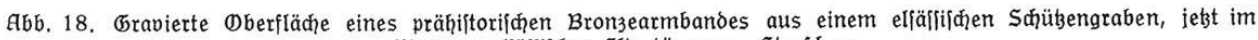

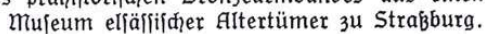

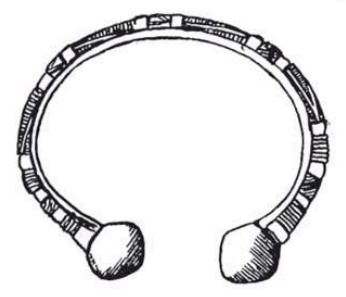

Gbb. 22. Bronzenes Armband aus der vorrömiןđ̧en Eilenzeit, gefunden in einem elfäfíifhen Sd)üzengraben, ietzt im Mujeum

el[äsificher Altertümer zu Straß̧burg.

BRACELET HALLSTAtTIEN déCOUVERT À HANgENBIETEN (BAS-RHIN) EN 1914 (DANS FORRER, ROBERT. " ELSÄSSISCHE ARCHÄOLOgIE IN DEN SCHÜTZENgRÄBEN ". MITTEILUNGEN DES RHEINISCHEN VEREINS FÜR DENKMALPFLEgE UND HEIMATSCHUTZ, 15 SEPTEMBER 1915, N² 2, P. 99, fig. 18, P. 106, fig. 22).

$\mathrm{Au}$ dire des ouvriers, de nombreux ossements avaient été découverts, appartenant vraisemblablement à plusieurs individus ${ }^{85}$. Cette découverte, probablement réalisée sur le «Rotten", est liée à la défense de la position de Kolbsheim "Lerchenberg ", à proximité d'une batterie de $100 \mathrm{~mm}^{86}$. Les objets ont été récupérés par le sous-officier Schramm de la $2^{\mathrm{e}}$ compagnie du $19^{\mathrm{e}}$ bataillon de dépôt de Strasbourg (Ersatz-Bataillon) Pionier-Bataillon Nr. 19). Sur la même commune, en effectuant des travaux en 1915, l'armée allemande a mis au jour des tessons protohistoriques (âge du Bronze et âge du Fer ${ }^{87}$. À Wolfisheim «Hunsrücken » (Bas-Rhin), une pointe de lance de l'âge du Fer a été retrouvée lors du creusement de tranchées en $1914^{88}$. Trois tombes de La Tène ancienne sont découvertes en janvier 1916 lors d'une opération identique par des prisonniers russes, à $100 \mathrm{~m}$ au nord du village de Blaesheim (Bas-Rhin) ${ }^{89}$. On note la présence parmi le mobilier d'un bracelet à tampons, d'un bracelet méandriforme et d'un torque à disques présentant des incrustations de corail (fig. $\left.\mathbf{n}^{\circ} \mathbf{8}\right)$. Ces travaux sont à mettre en relation avec la position avancée du « Gloeckelsberg » élaborée entre 1914 et $1916^{90}$. 


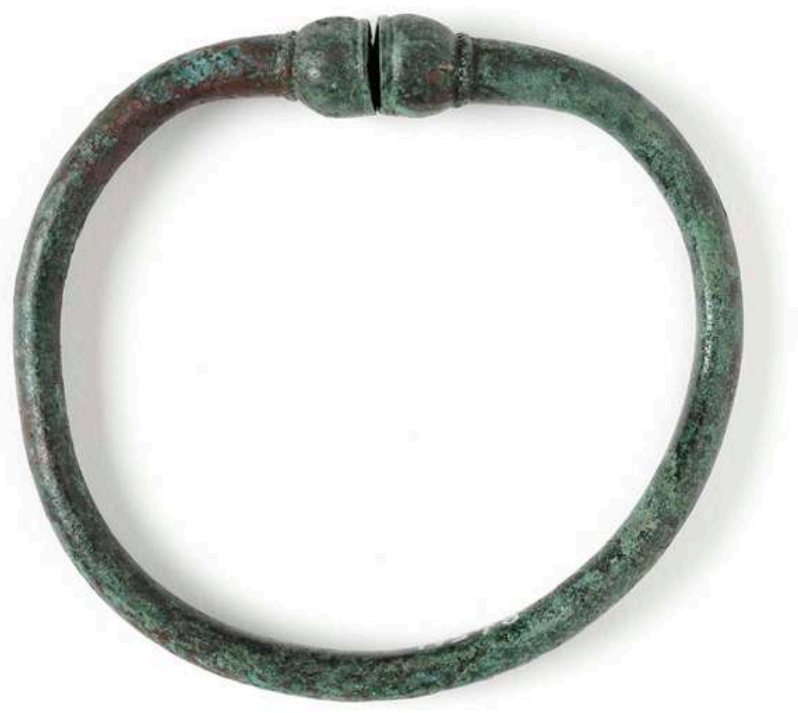

BRACELET LATÉNIEN dÉCOUVERT EN JANVIER 1916 À bLAESHEIM « GLOECKELSBERg » (BAS-RHIN).

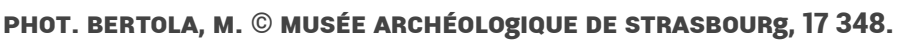

Les découvertes de sépultures du début du Moyen Âge sont nombreuses. À l'ouest du village d'Achenheim (Bas-Rhin), une dizaine de tombes mérovingiennes a été retrouvée à proximité de l'auberge du Tilleul, au lieu-dit «Totenallee », lors du creusement de tranchées entre janvier et février $1916^{91}$. Une partie du mobilier a pu être sauvegardée pour le musée et plusieurs interventions sur le terrain ont pu être menées par R. Forrer, Bottemer et Sulzberger, ces derniers assistants du musée ${ }^{92}$. À Wolxheim «Altbronn » (Bas-Rhin), c'est l'installation d'un poste de soins fin août 1914 à proximité de l'«Altenberg» qui est à l'origine de la découverte de tombes à dalles mérovingiennes pourvues de mobilier ${ }^{93}$ (fig. $\mathbf{n}^{\circ} \mathbf{9}$ ). R. Forrer et le chanoine Eugène Müller (1861-1948) visitent le site en novembre 1914 et en extraient céramique, perles en verre, boucles de ceinture et scramasaxe ${ }^{94}$. Plusieurs sépultures sont signalées à Holtzheim (Bas-Rhin). En août 1914, une tombe à dalles d'enfant (ou un sarcophage) a été mise au jour lors du creusement de tranchées ${ }^{95}$. Plus tard, en juin 1915, une sépulture à dalles et plusieurs squelettes sont également découverts sur le territoire de la commune, sans qu'un lien formel puisse être établi avec la découverte précédemment décrite ${ }^{96}$. La fouille méthodique réalisée à cette occasion sous la conduite de R. Forrer s'étend de part et d'autre de la tranchée et fait l'objet d'une visite du général Richard von Schubert (1850-1933) le 15 juin $1915^{97}$ (fig. $\mathbf{n}^{\circ}{ }^{10}$ ). La documentation de fouille est précise (plans, coupes et relevés). Le mobilier retrouvé en association (boutons en alliage cuivreux et couteaux en fer) permet de dater la nécropole de l'époque mérovingienne. Plusieurs inhumations sous dalles qui n'ont pas livré de mobilier ont été également mises au jour à Kolbsheim «Zwölfacker » (BasRhin) lors du renforcement de tranchées en septembre $1914^{98}$. Une copie du courrier 
d'information et un plan de situation réalisés par l'officier-ingénieur en charge des travaux de fortification de la position de la Bruche permettent de localiser la découverte et d'établir un lien avec la nécropole mérovingienne fouillée à proximité en $2010^{99}$. Ces aménagements appartiennent à la défense de la position de Kolbsheim «Lerchenberg», à proximité d'une série de batteries d'artillerie ${ }^{100}$. Enfin, quatre sépultures mérovingiennes sont découvertes lors du creusement de tranchées en janvier 1915 à Hangenbieten « Lœssière Jeuch » (Bas-Rhin), le long de la route qui mène à Achenheim ${ }^{101}$. Ces dernières permettent la défense sud de ce village ${ }^{102}$. Des fouilles complémentaires ont été menées au même endroit par Claude Schaeffer (1898-1982) en 1928.

Figure 9

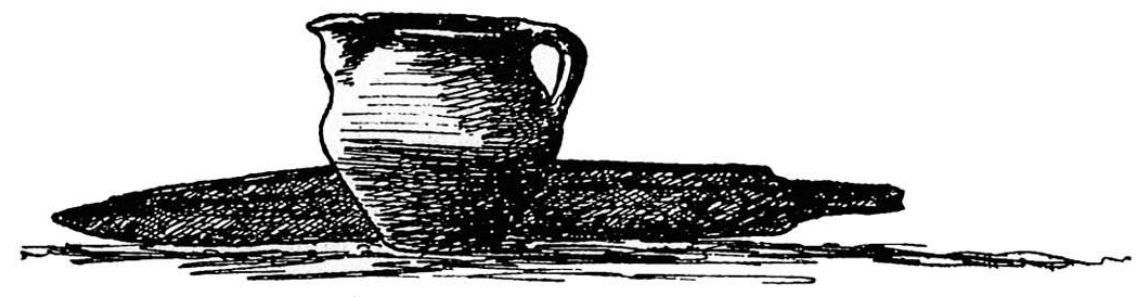

Gbb. 20. đönerne Methłanne und eifernes Säbeliđhert aus einem in einem elfäfiifhen Sđüutzengraben ausgehobenen Germanengrabe der Merowingerzeit.

MOBILIER DÉCOUVERT À WOLXHEIM « ALTBRONN » (BAS-RHIN) EN 1914 (DANS FORRER, ROBERT. « ELSÄSSISCHE ARCHÄOLOgIE IN DEN SCHÜTZENGRÄBEN ". MITTEILUNGEN DES RHEINISCHEN VEREINS FÜR DENKMALPFLEgE UND HEIMATSCHUTZ, 15 SEPTEMBER 1915, N², P. 103, fig. 20). 
Figure 10

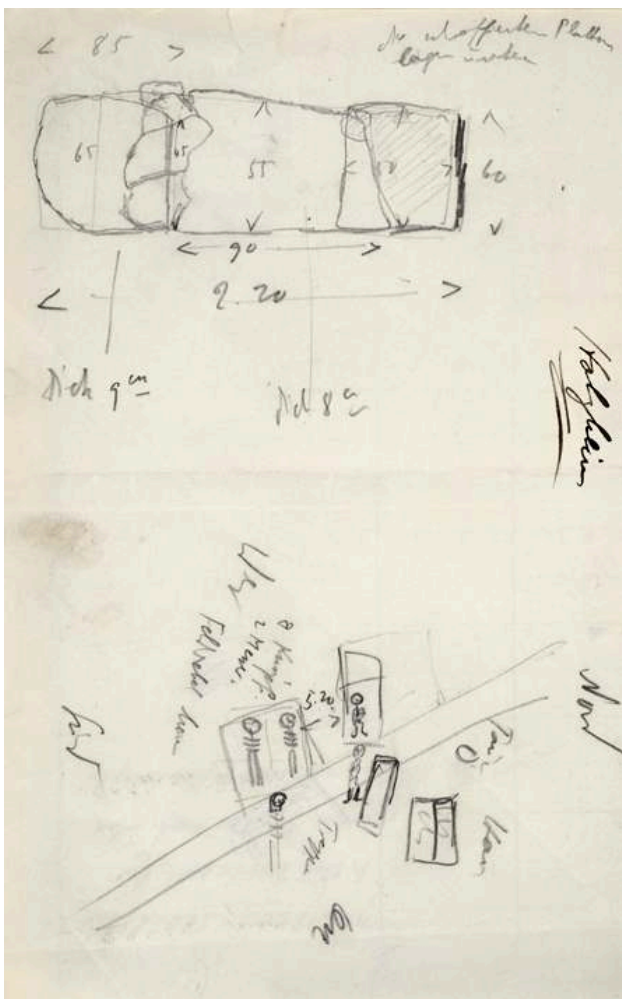

SÉPULtURES MÉRoVingIENNES déCOUVERTES À HOLTZHEIM (BAS-RHIN) EN 1915.

(c) MUSÉE ARCHÉologiQUE DE STRASBOURg, 18001.

Sur le sommet du «Scharrach» dominant le village de Scharrachbergheim (Bas-Rhin), la construction entre janvier et mars 1915 d'un poste de commandement bétonné, lié à l'importante défense allemande $\mathrm{du}$ massif ${ }^{103}$, entraîne la découverte de mobilier et de substructions à l'emplacement de levées de terre et de terrasses fossoyées (fig. $\left.\mathbf{n}^{\circ} \mathbf{1 1}\right)$. La coupe stratigraphique réalisée par le Service des fortifications du fort de Mutzig (Feste Kaiser Wilhelm II) permet de reconnaître le profil initial d'un fossé et d'identifier deux états dans la levée de terre qui a été surélevée ${ }^{104}$ (fig. $\mathbf{n}^{\circ} \mathbf{1 2}$ ). Les entrées correspondantes dans les collections du musée archéologique de Strasbourg concernent $\mathrm{du}$ mobilier gallo-romain (monnaie constantinienne et une fibule cruciforme) et du début de l'époque médiévale (céramique décorée et fragment de pot de poêle) ${ }^{105}$. Les observations permettent d'identifier un château à motte et non pas un système fortifié pré- ou protohistorique, voire antique ${ }^{106}$. Les murs retrouvés à l'extérieur de la motte, parfois interprétés par R. Forrer comme les vestiges d'une tour fortifiée antique du Bas-Empire, ne peuvent pas être datés en l'absence de mobilier et de documentation ${ }^{107}$. Enfin, la pointe de lance de la fin du Moyen Âge, découverte fin 1914 lors du creusement de tranchées à Wolfisheim (Bas-Rhin), est douteuse ${ }^{108}$. 
Figure 11

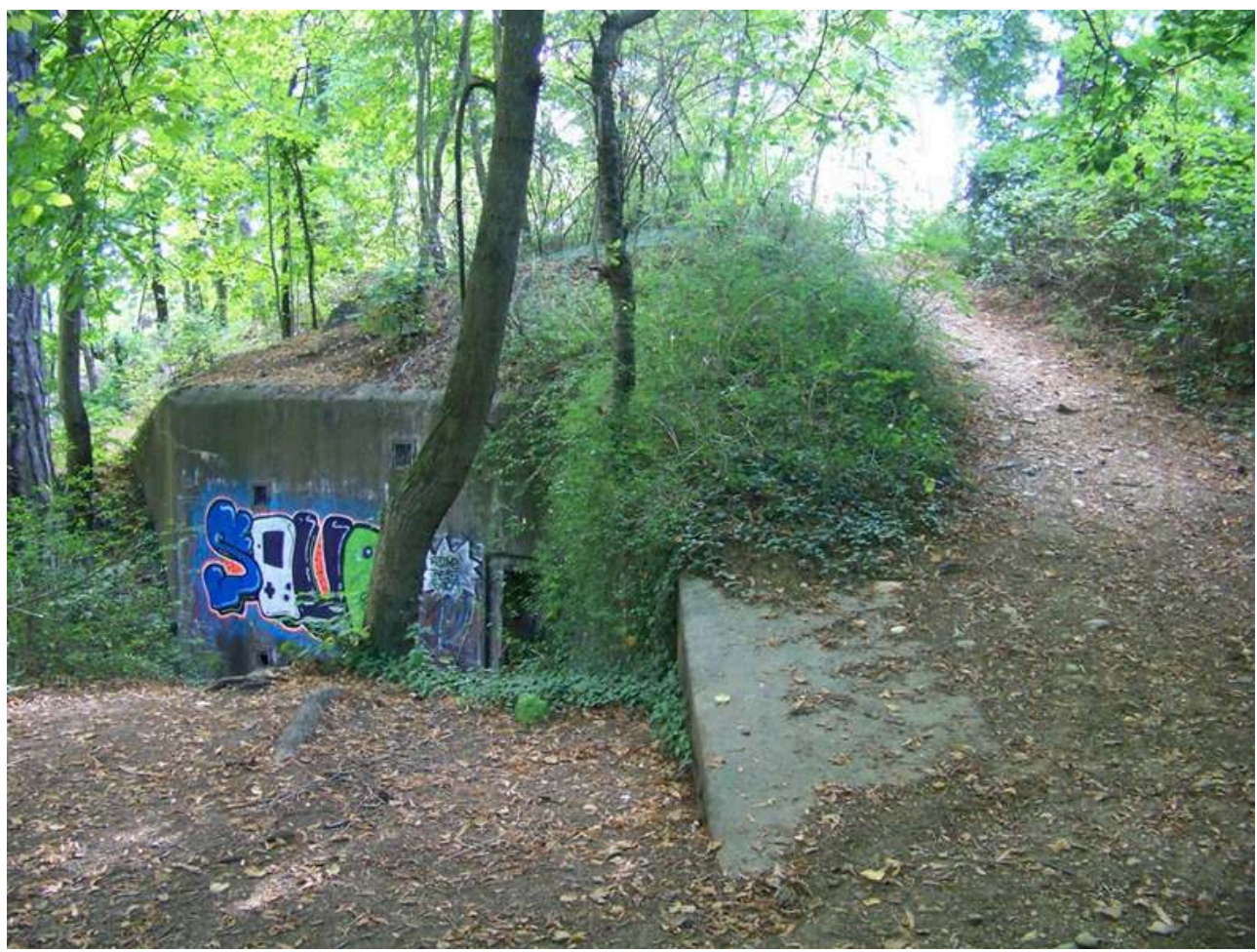

EMPLACEMENT DE LA DÉCOUVERTE DE SCHARRACHBERgHEIM-IRMSTETT « SCHARRACH » (BAS-RHIN) DE NOS JOURS.

PHOT. LANDOLT, M. (C) PAIR.

Figure 12

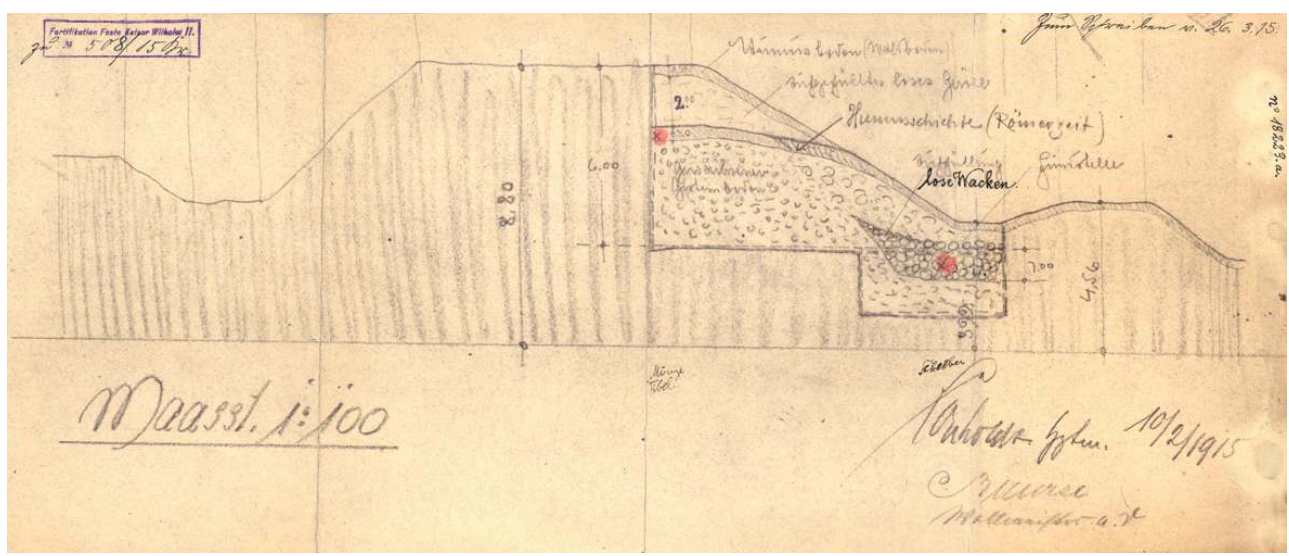

COUPE STRATIgRAPHIQUE, RÉALISÉE PAR LE SERVICE DES FORTIficATIONS DU FORT DE MUTZIg À SCHARRACHBERgHEIM-IRMSTETT « SCHARRACH » (BAS-RHIN) EN 1915.

(C) MUSÉE ARCHÉOLOgIQUE DE STRASBOURg.

La visite du général Eberhard von Claer (1856-1945), inspecteur du génie (Ingenieur und Pionier-Korps), met définitivement un terme aux travaux d'aménagement des positions fortifiées de la région de Strasbourg en avril 1916: plus d'une centaine de kilomètres de tranchées avaient été creusées, environ un millier d'abris bétonnés de différents types coulés et des centaines de positions d'artillerie creusées ${ }^{109}$. Cette suspension des travaux met fin aux découvertes archéologiques autour de Strasbourg. 


\section{Les découvertes du sanctuaire gallo-romain du " Donon » (1916-1917)}

Une collaboration plus active s'engage parfois avec certains officiers allemands intéressés par l'archéologie. Tel est le cas pour le sanctuaire gallo-romain du "Donon » ${ }^{110}$ lorsque, sur la commune de Grandfontaine (Bas-Rhin), à l'automne 1916 et au printemps 1917, l'armée allemande installe au sommet de la montagne un poste d'observation et une plate-forme pour une pièce d'artillerie antiaérienne. Des fragments sculptés, dont deux groupes de Jupiter cavalier à l'anguipède, un chapiteau décoré, une dédicace à Mercure et un fragment de borne milliaire, sont mis au jour. À l'initiative de R. Forrer et avec l'aide du conservateur des Monuments historiques Johann Knauth (1864-1924), ces sculptures sont transférées au musée par les autorités pour assurer leur sauvegarde sous le contrôle du lieutenant Fritz Pöhlmann qui dirige les opérations sur place. Ses connaissances des enceintes protohistoriques du sud-ouest de l'Allemagne ${ }^{111}$ lui permettent d'établir un relevé de l'enceinte ceinturant le site. Les coupes d'arbres qui ont été réalisées au sommet de la montagne dans un but militaire ont rendu en effet nettement visible une levée de terre mêlée de blocs de pierre qui enserre le sommet et la plate-forme inférieure. Des fouilles, effectuées quelques années après le conflit par R. Forrer sur le plateau au nord du temple et à l'extrémité ouest du plateau, révélèrent une occupation protohistorique qui livra de nombreux outils de mouture et des tessons protohistoriques ${ }^{112}$.

\section{La tombe à char hallstattienne d'Ohnenheim (1917)}

Figure 13
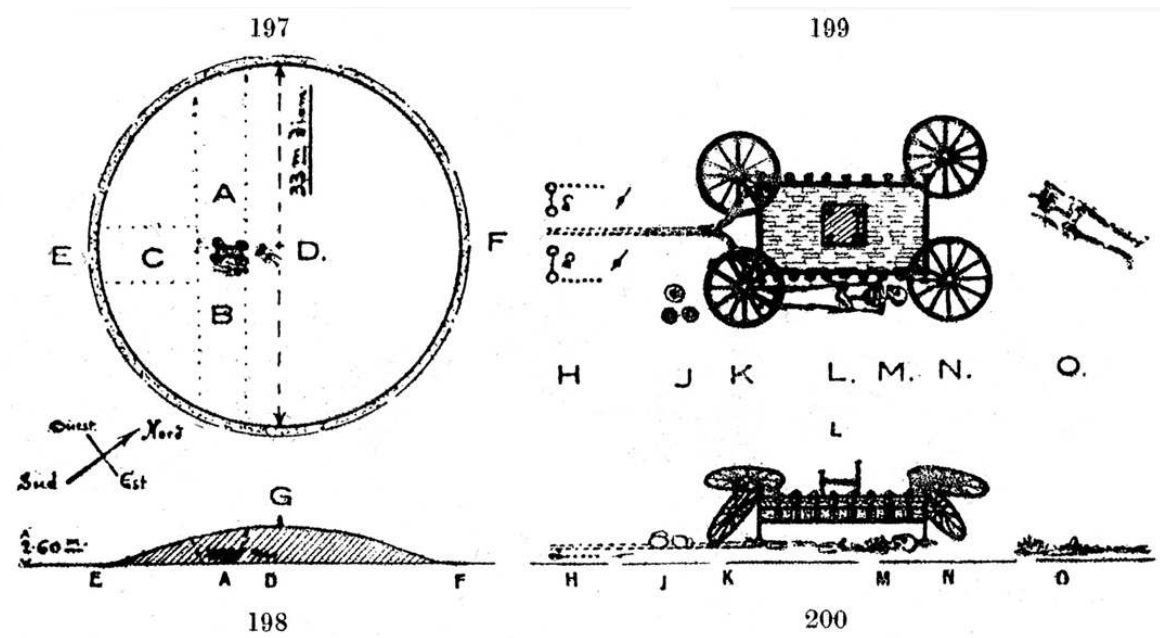

Fig. 197-200. Lo tumulus ot la sépulture ì ohar d'Ohnonheim, 197 plan, 198 coupe du tumulus, 199 reconstitution de la sépulture à char vue d'en haut, 200 vue do profil.

TOMBE À CHAR D'OHNENHEIM « NIEDERSCHLEY » (BAS-RHIN) EN 1917 (DANS FORRER, ROBERT. « UN CHAR DE CULTE À QUATRE ROUES ET TRÔNE, DÉCOUVERT DANS UN TUMULUS GAULOIS À OHNENHEIM (ALSACE) ". CAHIERS D'ARCHÉOLOgIE ET D'HISTOIRE D'ALSACE, MAI 1921, N 45-48, P. 1199, fig. 197-200).

Mais l'une des trouvailles les plus spectaculaires est faite à Ohnenheim " Niederschley " (Bas-Rhin) près de Sélestat ${ }^{113}$. Au printemps 1917, un rapport est transmis à R. Forrer 
signalant qu'un tumulus et une sépulture avaient été éventrés cinq mois auparavant lors d'exercices de tir par des soldats de la $8^{\mathrm{e}}$ compagnie du $3^{\mathrm{e}}$ régiment bavarois d'infanterie, qui avaient "excavé" deux énormes tranchées à travers le tertre constitué par ces deux vestiges ${ }^{114}\left(\right.$ fig. $\left.^{\circ} \mathbf{n}^{\mathbf{1}} \mathbf{1 3}\right)$. Les objets récupérés par les Bavarois lors des excavations et les quelques notes prises par le lieutenant Steiner à cette occasion sont remis au musée par l'intermédiaire du conservateur des Monuments historiques Johann Knauth ${ }^{115}$. Un autre tumulus de la nécropole connut le même sort quelque temps après la guerre : des soldats français remanièrent en 1919 un autre tertre pour s'en servir comme butte de tir (tumulus n¹5). L'étude du site, reprise en 1920 par R. Forrer, permit d'identifier une riche sépulture hallstattienne comportant un char à quatre roues (fig. $\left.\mathbf{n}^{\circ} \mathbf{1 4}\right)$.

Figure 14

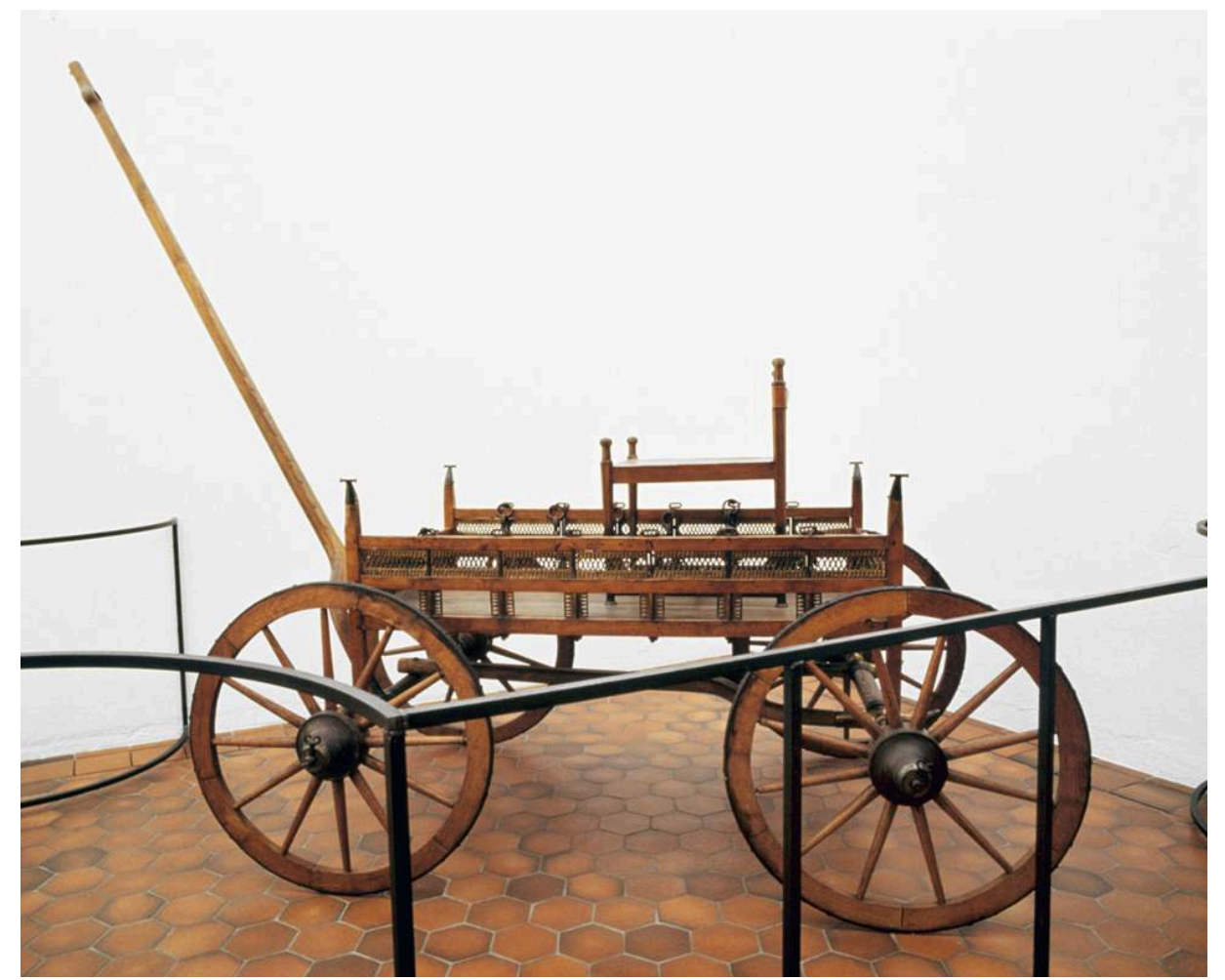

RECONSTITUTION DU CHAR PROTOHISTORIQUE D'OHNENHEIM “ NIEDERSCHLEY " (BAS-RHIN) RÉALISÉE DANS LES ANNÉES 1920 À PARTIR DES ÉLÉMENTS ORIgINAUX EN BRONZE DÉCOUVERTS EN 1917.

(C) MUSÉE ARCHÉOLogIQUE DE STRASBOURg.

\section{Des sites de hauteur également à l'honneur}

Le déboisement du massif du Mont Sainte-Odile (Bas-Rhin), réalisé entre 1914 et 1916 après une tempête qui occasionna aussi divers dégâts au Mur païen, offre à Robert Forrer l'opportunité de poursuivre ses observations sur un site qu'il connait bien ${ }^{116}$. Il a en effet consacré à la fin du XIX ${ }^{\mathrm{e}}$ siècle une importante étude ${ }^{117}$ à cette vaste enceinte en pierres sèches qui ceinture le sommet du Mont Sainte-Odile sur plus de $10 \mathrm{~km}$ de long, à ses carrières et au plateau sommital du couvent fondé au haut Moyen Âge. Il est aussi le créateur du petit musée où sont rassemblées les trouvailles antiques faites sur la montagne au fil des décennies. 
Reprenant les observations réalisées bien avant la guerre par Charles Frédéric Faudel (1826-1893) et Marie Gustave Bleicher (1838-1901), R. Forrer s'intéresse aussi au « Hartmannswillerkopf » à Hartmannswiller (Haut-Rhin) dans le cadre de son étude sur les enceintes fortifiées d'Alsace ${ }^{118}$. Ce site est, d'après R. Forrer, l'archétype des " enceintes vitrifiées». Malheureusement, les combats meurtriers ayant marqué ce sommet durant toute la guerre ont entièrement détruit les vestiges de cette enceinte. Le promontoire qui surplombe la plaine d'Alsace a fait partie des sites de guerre classés dès le début des années 1920 au titre des Monuments historiques, avec la création d'un monument commémoratif et d'une nécropole nationale.

\section{Les sites mis au jour en Lorraine}

En Lorraine, la recherche semble se concentrer sur quelques sites importants.

\section{Une sépulture gallo-romaine dans la région de Sarrebourg (1914)}

Tout au début du conflit, le site de la bataille de Sarrebourg (Moselle) livre une urne funéraire romaine en pierre, composée de deux éléments demi-sphériques contenant un vase et des ossements calcinés (fig. $\mathbf{n}^{\mathbf{0}} \mathbf{1 5}$ ). Cette découverte en pleine bataille des 19-20 août 1914, lors de la mise en place d'une position d'artillerie ${ }^{119}$, est due à un officier mort peu après au combat.

Figure 15

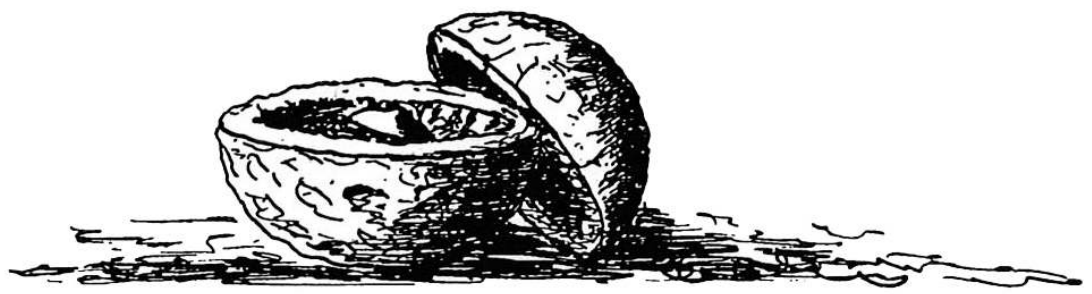

Gъb. 19. Römilđhes Brandgrab; Steinurne mit Alđeninkalt, ausgehoben während der Sđ̧lađt bei Saarburg.

SÉPULTURE gALLO-ROMAINE DÉCOUVERTE LORS DE LA BATAILLE DE SARREBOURg (MOSELLE) EN 1914 (DANS FORRER, ROBERT. " ELSÄSSISCHE ARCHÄOLOgIE IN DEN SCHÜTZENGRÄBEN ». MITTEILUNGEN DES RHEINISCHEN VEREINS FÜR DENKMALPFLEg UND HEIMATSCHUTZ, 15 SEPTEMBER 1915, N², P. 102, fig. 19).

\section{Les ateliers de sigillée d'Argonne (1914-1916)}

En Argonne, dans le « Bois de Cheppy », à l'ouest d'Avocourt (Meuse), d'importants lots de céramiques antiques, notamment de sigillée de l'Antiquité tardive, ont été découverts par le $125^{\mathrm{e}}$ régiment d'infanterie de Landwehr, lors de l'aménagement de positions pendant l'hiver 1914-1915, puis au mois d'août 1915 et au printemps 1916. Les échantillons prélevés et de la documentation (coupe stratigraphique, description) ont été envoyés au musée archéologique de Strasbourg et à l'université de Berlin par l'intermédiaire, notamment, du colonel Walther commandant ce régiment ${ }^{120}$ (fig. $\mathbf{n}^{\circ}$ 16). Ces fouilles, certes rapides mais méthodiques, ont permis de constituer des 
collections de référence dans le domaine de la céramologie antique. C'est ainsi qu'à partir de 1915, l'étude des ateliers de potiers gallo-romains d'Argonne a pris une nouvelle ampleur grâce à la création de deux pôles de recherche distincts, le premier établi en France autour de Georges Chenet (1881-1951) et le second, en Allemagne, autour de Wilhelm Unverzagt (1892-1971) ${ }^{121}$. Peu avant la Première Guerre mondiale, ce jeune archéologue allemand entreprend une vaste enquête sur la céramique sigillée gallo-romaine décorée à la molette, à la demande du directeur de la RömischGermanische Kommission Emil Ritterling (1861-1928). La guerre interrompt le travail de W. Unverzagt, qui est mobilisé et combat dans les Flandres, en Pologne ainsi que dans les Carpates. Grièvement blessé en 1916 et démobilisé, il travaille de nouveau pour la Römisch-Germanische Kommission qui le charge cette fois de recherches archéologiques en Belgique et dans le nord de la France ; il y fouille notamment en 1918 la fortification du Bas-Empire de Famars (Nord), en collaboration avec l'archéologue Gerhard Bersu (1889-1964).

\section{Figure 16}

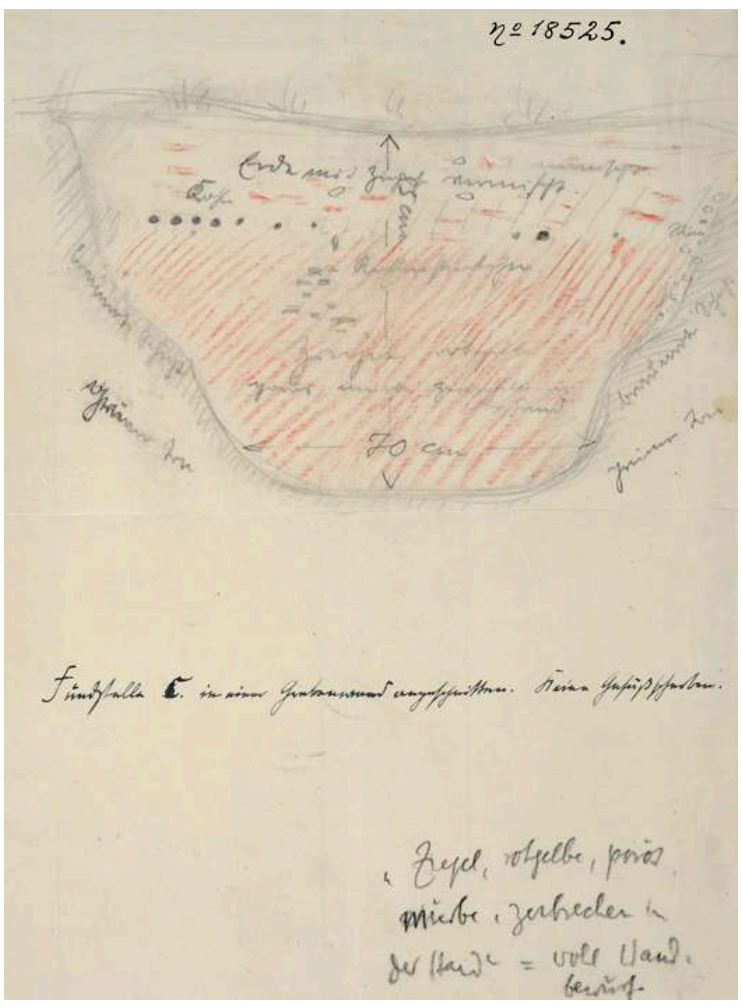

COUPE STRATIgRAPHIQUE D'UNE FOSSE gALLO-ROMAINE DE L'ATELIER D'AVOCOURT « BOIS DE CHEPPY » (MEUSE) ENVOYÉE EN 1915 AU MUSÉE ARCHÉologIQUE DE STRASBOURg. ๑ MUSÉE ARCHÉologiQue de STRASBOURg, 18525.

Curieusement, si les hostilités ont dans un premier temps mis un frein aux recherches sur la céramique entreprises par W. Unverzagt, le déroulement des combats lui permet ensuite de disposer de données nouvelles sur le sujet. Le hasard veut en effet que le front stabilisé traverse les ateliers de poterie d'Argonne, qui sont précisément le lieu de production de la sigillée décorée à la molette. Le creusement de positions enterrées amène donc de nombreuses découvertes qui font l'objet d'observations de la part de plusieurs officiers allemands, le colonel Walther (déjà mentionné), le sous-lieutenant G. Strohm et un certain Bach ${ }^{122}$. Durant l'hiver 1914-1915, une tranchée traverse ainsi 
l'atelier du "Bois de Cheppy ", mettant au jour plusieurs fours et dépotoirs de potiers ainsi qu'une importante quantité de céramique. G. Strohm consacre de son côté son temps libre à l'étude d'un autre atelier situé au nord du village d'Avocourt, lui aussi mis au jour lors de travaux de terrassement. G. Strohm fournit un rapport écrit de ses découvertes à Wilhelm Unverzagt qui réalise la première synthèse sur la sigillée décorée à la molette, parue immédiatement après le conflit ${ }^{123}$. Cet ouvrage resta inégalé pendant deux décennies et ne fut dépassé qu'en 1941, par le travail de Georges Chenet, qui est encore un ouvrage de référence ${ }^{124}$. À son retour de la guerre, le chercheur français dut constater la perte d'une partie de ses archives et de sa collection conservées dans sa maison du Claon (Meuse) ${ }^{125}$.

Plus tard, en mai 1918, le sous-lieutenant G. Strohm fut de nouveau lié à une découverte archéologique en Argonne dans une tranchée abandonnée, alors qu'il stationnait dans un cantonnement près de Vienne-le-Château (Marne). Après avoir déblayé la tranchée et complété la coupe, il identifia une stratigraphie qui livra une grande quantité de fragments de verre. Initialement identifiés par le fouilleur comme une verrerie de la fin de l'Antiquité, le réexamen du mobilier quelques années plus tard par l'archéologue allemand Siegfried Loeschke (1883-1956) révéla qu'il s'agissait de verre du début de l'époque moderne ${ }^{126}$.

\section{Le bassin en bronze mérovingien d'Avocourt « Champ des Bierres » (1915 ?-1921)}

Les travaux de Georges Chenet en Argonne après la guerre ont permis de mettre en évidence du mobilier dans la zone des combats ${ }^{127}$. En juin 1921, ce dernier découvre à Lachalade «Le Princier» (Meuse) un petit buste d'éphèbe antique en alliage cuivreux parmi les déblais d'un cratère d'explosion ${ }^{128}$. Un peu plus tard, au moins d'août, il découvre un bassin métallique à Avocourt "Champ des Bierres » ${ }^{129}$. Ce bassin à bord perlé en alliage cuivreux, attribuable au $\mathrm{VI}^{e}$ siècle, est retrouvé dans une tranchée allemande se trouvant sur un site antique et une nécropole mérovingienne qu'il avait auparavant déjà explorés en 1909. L'objet, probablement issu d'une sépulture, se trouvait dans une niche creusée dans la paroi de la tranchée. L'élément de vaisselle avait été découvert lors des excavations menées par les troupes allemandes, vraisemblablement vers 1915, puis placé volontairement dans une niche comblée de sable afin de le protéger. Comme pour le four de Vauquois des "Allieux", découvert à proximité par les terrassiers français, la volonté de protéger les vestiges mérite d'être soulignée.

\section{Quelques découvertes autour de Metz (1915)}

Quelques autres découvertes sont à signaler autour de Metz pour l'année 1915, dont celle d'un squelette de saurien lors du creusement d'une deuxième position par le $30^{\mathrm{e}}$ régiment d'infanterie de Landwehr, au nord de Cheminot (Kemnat) (Moselle); comme aucun spécialiste de la Commission géologique (Geologischen Landesanstalt) de Strasbourg ne voulut se déplacer, J. B. Keune établit un croquis rapide, fit un relevé des ossements et les fit acheminer au musée de Metz ${ }^{130}$.

À l'automne 1915, des travaux d'aménagement des fortifications d'intervalles de l'ouvrage de «Leipzig " près de la ferme du même nom à Châtel-Saint-Germain (Sankt 
German) (Moselle) amènent la découverte de structures gallo-romaines, notamment une cave maçonnée ${ }^{131}$. J. B. Keune vint sur place et fit prendre quelques clichés, dont l'un fut publié par Émile Linckenheld (1880-1976) dans la synthèse qu'il consacra aux découvertes faites en Lorraine de 1915 à $1928^{132}$ (fig. $\mathbf{n}^{\circ} \mathbf{1 7}$ ).

Figure 17

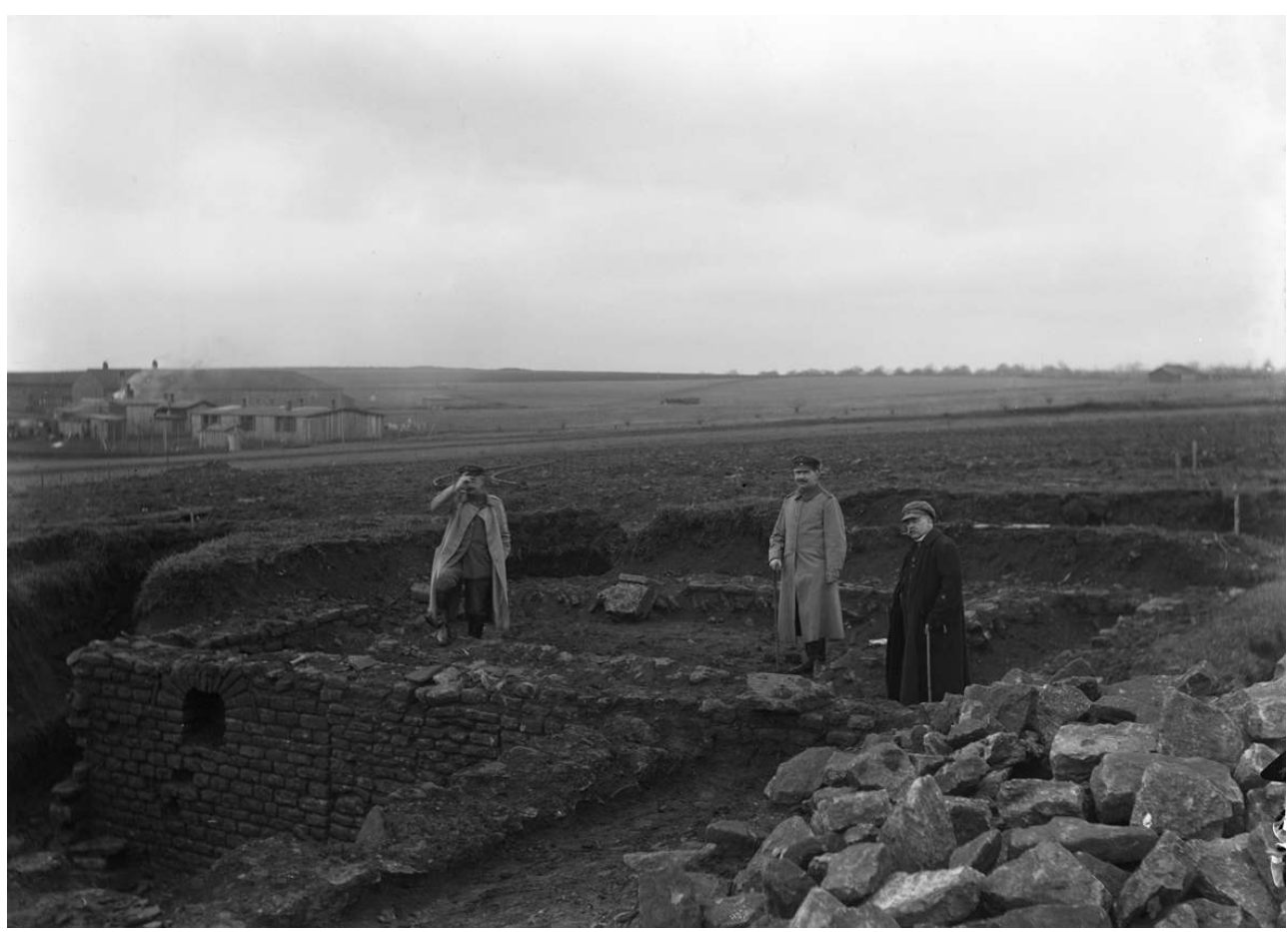

FOUILLES DE CHÂTEL-SAINT-GERMAIN « FERME DE LEIPZIg » (MOSELLE) LE 30 dÉCEMBRE 1915.

(c) MUSÉE DE LA COUR D'OR-METZ MÉTROPOLE, KM 359.

D'autres trouvailles sont mentionnées dans une publication allemande de 1915 sans que les lieux et dates des découvertes - peut-être localisées dans la région de Metz - ne soient malheureusement précisés ${ }^{133}$. Évoquées par un officier supérieur bavarois membre de la société d'histoire de Bamberg (Allemagne, Bavière), elles sont à mettre en relation avec des occupations antiques (murs, tuile estampillée, céramique sigillée, etc.) et médiévales (cimetière paroissial).

\section{Les sarcophages mérovingiens de Varvinay (1915)}

Les zones d'intervention ont souvent été fluctuantes et ont varié en fonction de leurs travaux respectifs et des avancées/reculs de la ligne de front. Sur le Saillant de SaintMihiel, à Varvinay "Bois des Livrées» (Meuse), deux sarcophages en pierre de Savonnières ont été retrouvés en mai 1915, lors de la construction d'un bâtiment léger (pavillon de détente) dans le camp du III ${ }^{\mathrm{e}}$ bataillon du $4^{\mathrm{e}}$ régiment bavarois d'infanterie de réserve, à proximité des baraquements de l'état-major. La découverte, décrite par le caporal Elser Hans, artiste et biologiste, a fait l'objet de plusieurs visites de J. B. Keune en juin et en août ${ }^{134}$. Un autre militaire dénommé Schacht, artiste et enseignant, a joué un rôle dans cette découverte mais son grade et sa fonction restent inconnus.

Le premier sarcophage était brisé. Le second, complet, renfermait une sépulture féminine associée à cinq autres crânes humains (fig. n¹8). En 1992, deux autres 
sarcophages appartenant à cette nécropole mérovingienne furent découverts à proximité lors de travaux forestiers ${ }^{135}$. Au niveau de Flassigny (Meuse), une autre nécropole, déjà connue en 1909 , a fait l'objet d'une étude complémentaire ${ }^{136}$, dans un secteur de l'arrière-front au nord de la Meuse où les troupes allemandes sont restées pendant toute la guerre. Une vingtaine de sépultures gallo-romaines auraient été découvertes à cette occasion.

Figure 18

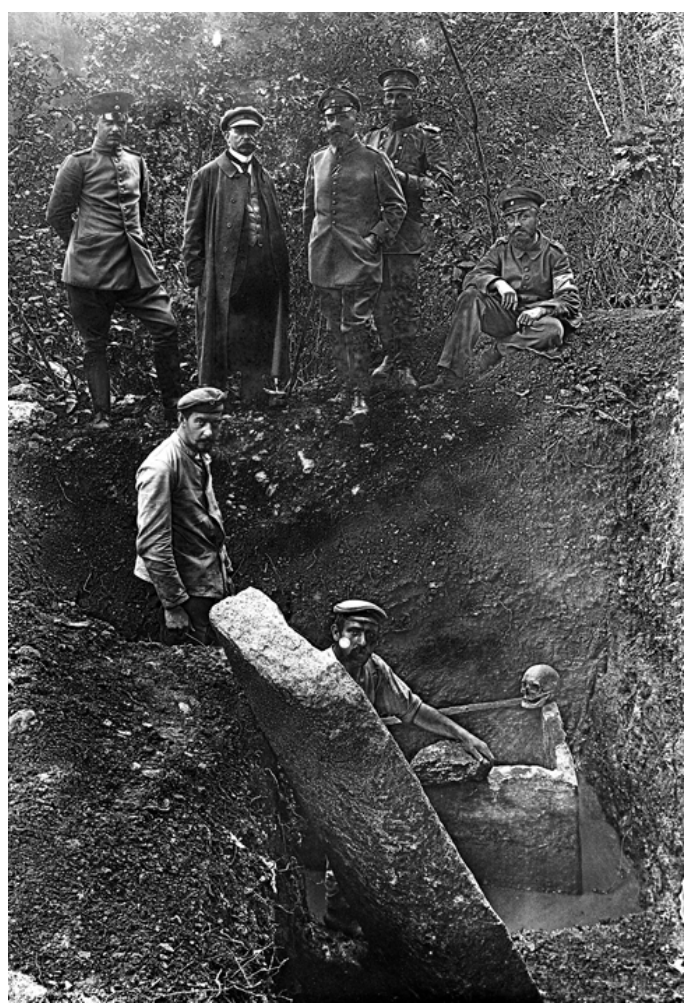

FOUILLES DE VARVINAY « BOIS DES LIVRÉES » (MEUSE) LE 13 AOÛT 1915.

(c) MUSÉE DE LA COUR D'OR-METZ MÉTROPOLE, KM 209.

L'autel gallo-romain de Norroy-lès-Pont-à-Mousson (1916) 
Figure 19

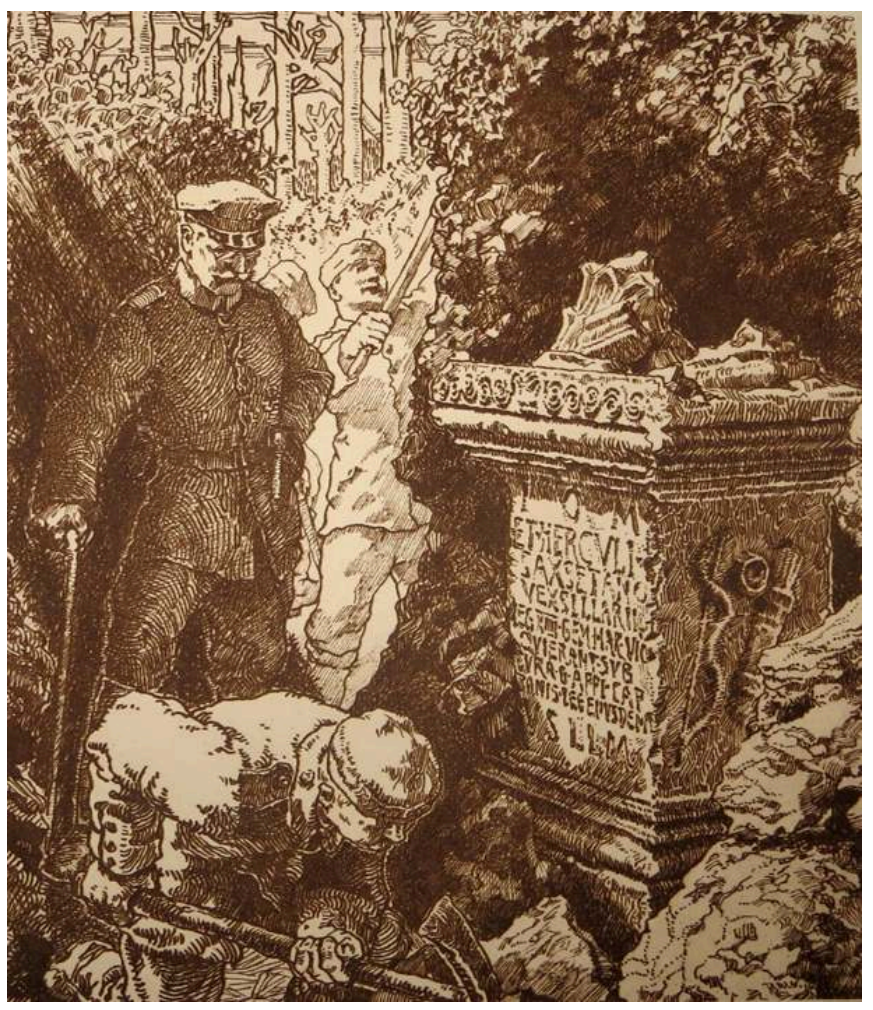

DÉCOUVERTE DE L'AUTEL gALLO-ROMAIN DE NORROY-LÈS-PONT-À-MOUSSON (MEURTHE-ET-MOSELLE) EN 1916 (DESSIN W. VOLTMER DANS ZWISCHEN MAAS UND MOSEL - ARMEE-ABTEILUNG VON STRANTZ. SIEgBURg : DEUTSCHE PHOTOgRAVUR A. G., 1917). 
Figure 20

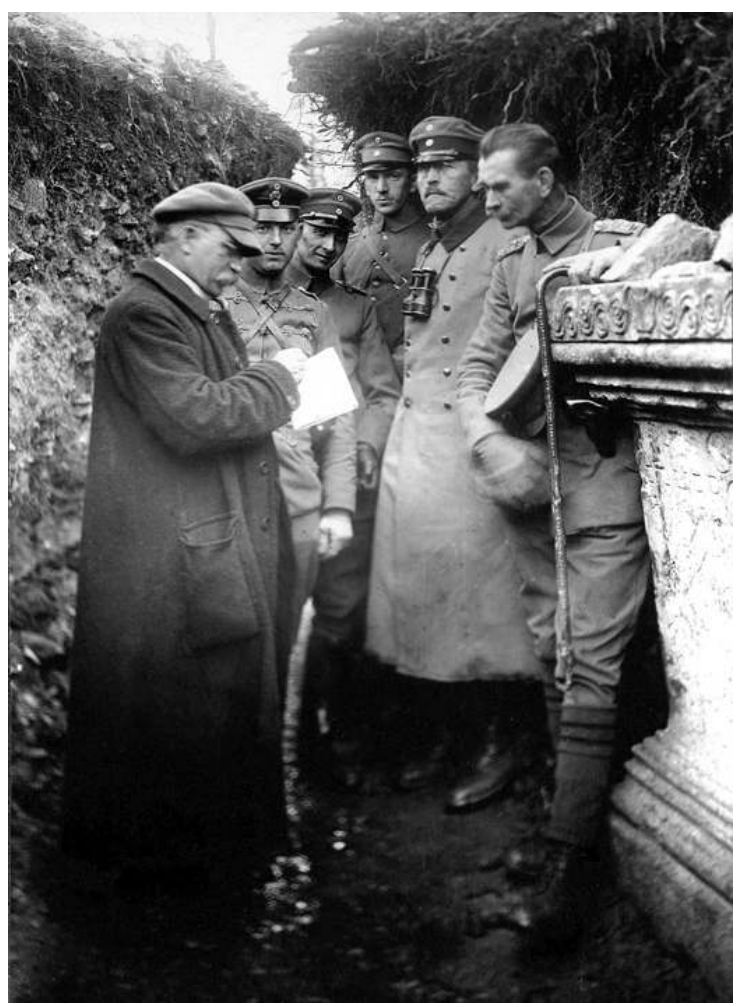

AUTEL gALLO-ROMAIN DE NORROY-LÈS-PONT-À-MOUSSON (MEURTHE-ET-MOSELLE) LE 15 AVRIL 1916. (C) MUSÉE DE LA COUR D'OR-METZ MÉTROPOLE, KM 439.

Le dégagement d'un remarquable autel gallo-romain à Norroy-lès-Pont-à-Mousson (Meurthe-et-Moselle) par le $93^{\mathrm{e}}$ régiment d'infanterie de Landwehr ou le $1^{\mathrm{er}}$ régiment d' Ersatz de Landwehr ${ }^{137}$ en décembre 1915 ou au début de 1916 constitue sans doute l'une des découvertes les plus remarquables pour la Lorraine ${ }^{138}$. Ses faces latérales sont ornées d'un arc et d'un carquois en relief et la face principale porte une dédicace à Jupiter et Hercule Saxanus indiquant qu'elle a été offerte par des vexillaires et des cohortes auxiliaires commandées par Lucius Pompeius Secundus, de la XIVe légion romaine (Legio XIV Gemina). La trouvaille se situe à environ $100 \mathrm{~m}$ des lignes adverses, dans les carrières de Norroy, où des découvertes avaient déjà été signalées. J. B. Keune se rend sur place le 15 avril 1916 : pour protéger la sculpture de toute atteinte, l'autel a été posé sur la face épigraphique et recouvert de terre ainsi que de blocs de pierre par l'archéologue avec l'aide du lieutenant Stolle et du sous-officier F. Walter, dans le civil archiviste de la ville de Mannheim (Allemagne, Bade-Wurtemberg) (fig. $\left.\mathbf{n}^{\circ} \mathbf{1 9}\right)$ (fig. $\mathbf{n}^{\circ} \mathbf{2 0}$ ). Cette protection se révéla pourtant insuffisante car l'autel eut à souffrir d'un bombardement en septembre : un projectile perça sa protection, enlevant deux grands éclats dans les parties supérieure et inférieure du monument, ainsi que de nombreux autres plus petits. J. B. Keune décida alors son transfert vers Metz et la sculpture fit son entrée dans les collections le 10 octobre 1916, où le directeur put l'étudier en détail ${ }^{139}$ (fig. ${ }^{\circ} 21$ ). 
Figure 21

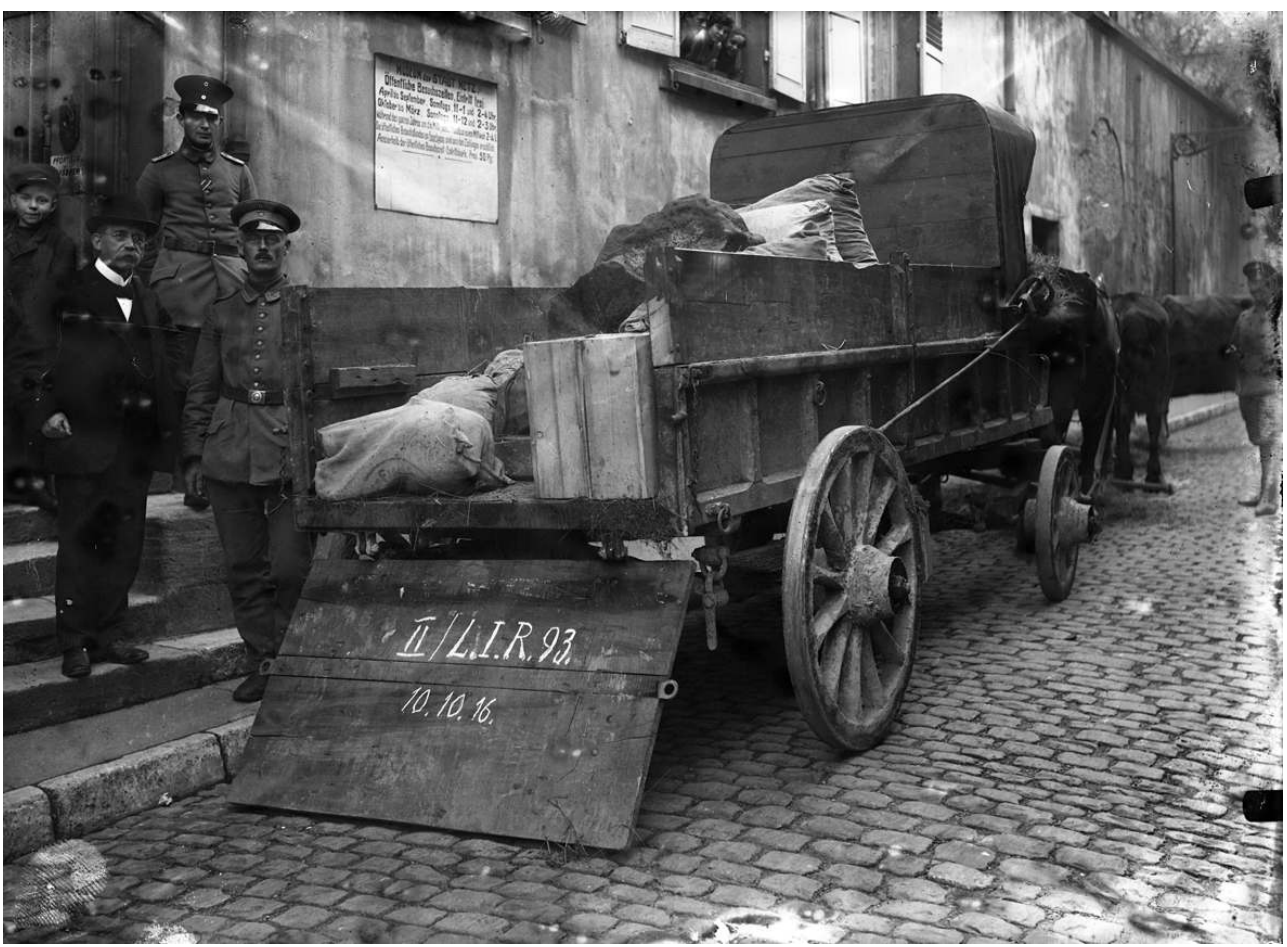

TRANSPORT DE L'AUTEL GALLO-ROMAIN DE NORROY-LÈS-PONT-À-MOUSSON (MEURTHE-ET-MOSELLE) AU MUSÉE DE METZ (MOSELLE) LE 10 OCTOBRE 1916.

C C MUSÉE DE LA COUR D'OR-METZ MÉTROPOLE, KM 553.

\section{Les fouilles de l'agglomération antique de Senon (1917)}

Par ailleurs, secondé par Friedrich Drexel (1885-1930), assistant à l'Institut archéologique de Francfort-sur-le-Main (Allemagne, Hesse), mobilisé avec le modeste rang de caporal, Heribert Reiners (1884-1956) dirige les fouilles de Senon (Meuse) en mai 1917 sur le site, connu depuis le début du XIX ${ }^{\mathrm{e}}$ siècle ${ }^{140}$. Ces recherches ont été réalisées dans le cadre de l'aménagement d'une ligne fortifiée, appelée Position Kriemhild (Kriemhild-Stellung), dont les travaux ont été effectués en 1916-1917 conformément au directives de l'état-major général allemand. Ces travaux, menés par des militaires allemands et des prisonniers russes, ont permis de mettre au jour une enceinte quadrangulaire (castellum), un complexe thermal et un bâtiment public rectangulaire (attribué aux vestiges d'une curie par les fouilleurs) de l'agglomération antique d'Amel-sur-l'Étang/Senon ${ }^{141}$. La fouille de l'enceinte quadrangulaire $(50 \mathrm{~m}$ de côté) du «Bourge » a permis de mettre en évidence une série de fragments d'éléments d'architecture et de monuments funéraires réemployés dans la fondation de l'enceinte du Bas-Empire. Une grande partie des éléments lapidaires sont transférés au dépôt de la Porte des Allemands à Metz avant d'être déposés au musée de Verdun après la guerre $^{142}$ (fig. $\mathbf{n}^{\circ} \mathbf{2 2}$ ). Les fouilles sont cependant interrompues après quelques semaines à cause d'un bombardement, l'armée française ayant probablement confondu les fouilles avec les travaux de construction de la position défensive. Il est important de mentionner la publication exhaustive des observations de la fouille dès 1918 sur l'ordre du commandement de la $5^{\mathrm{e}}$ armée allemande ${ }^{143}$. Après la guerre, Georges Chenet visite en avril 1921 le site et ramasse de nombreux objets et fragments de céramique dans les 
déblais de fouille de l'enceinte ${ }^{144}$. Afin que ces importants vestiges ne servent ni de dépotoir ni de carrière de matériaux pour la reconstruction du village, les vestiges de la fortification sont classés au titre des Monuments historiques le 16 avril 1923.

Figure 22

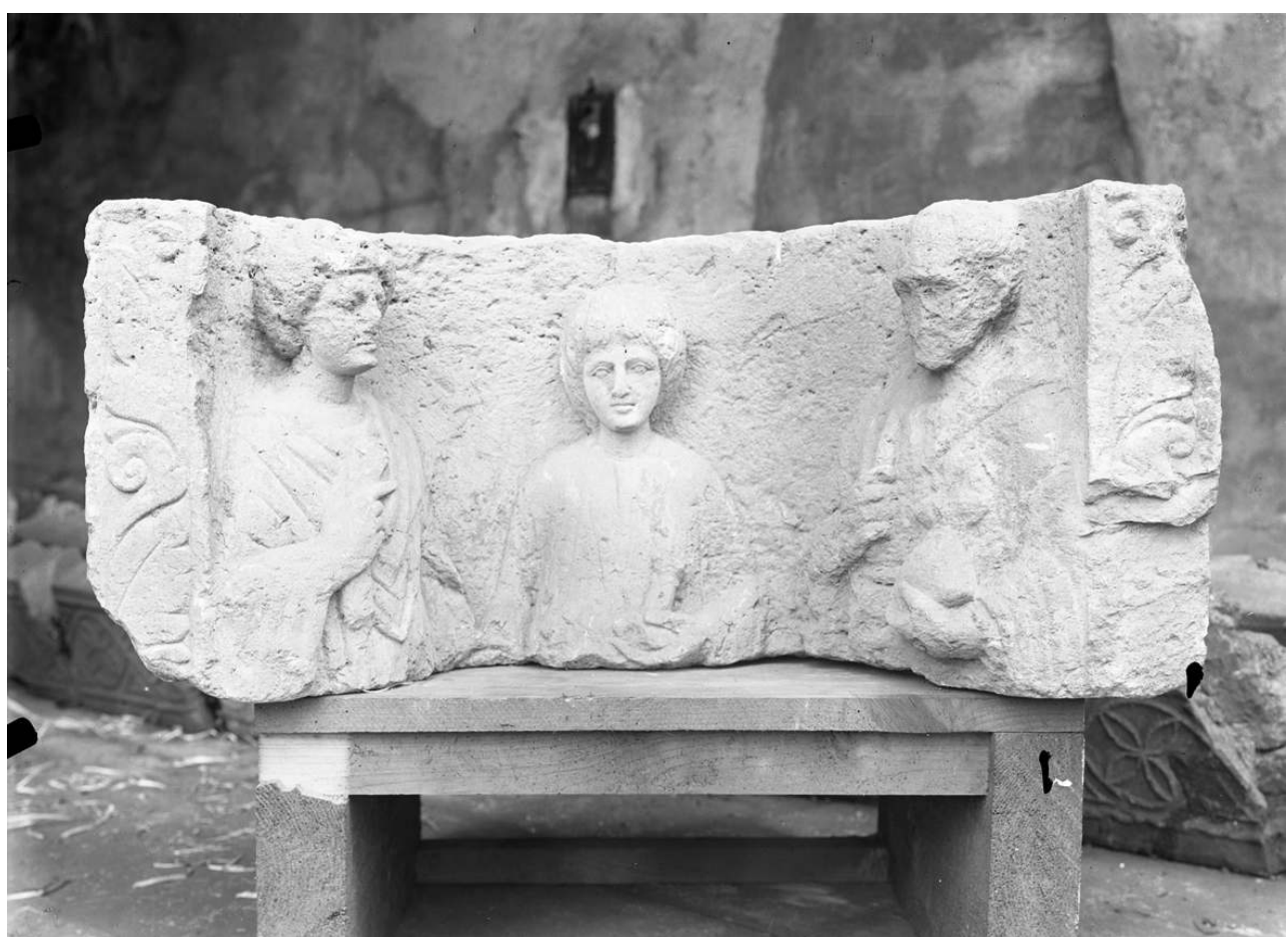

FRAgMENT DE STÈLE FUNÉRAIRE gALLO-ROMAINE RETROUVÉ DANS LA FONDATION DE L'ENCEINTE DU BAS-EMPIRE DE SENON « BOURgE » (MEUSE) PHOTOgRAPHIÉ LE 25 MAI 1918. @) MUSÉE DE LA COUR D'OR-METZ MÉTROPOLE, KM 83.3.

Ces recherches contribuent ainsi à apporter un éclairage nouveau sur l'histoire de l'archéologie au cours du premier conflit mondial. Les données actuelles mettent en évidence deux logiques patrimoniales divergentes appliquées par les belligérants. La première, celle de la France, relève d'une situation d'urgence où la priorité a été donnée à la seule sauvegarde des biens culturels existants, laissant de côté les découvertes nouvelles. La seconde, celle de l'Allemagne, est plus complexe : dans le cadre du Kunstschutz, les découvertes ont été considérées comme des biens appartenant au patrimoine universel, exploitées lorsque cela était possible pour en assurer la transmission et l'actualisation des connaissances; elles n'ont toutefois pas toujours échappé à leur valorisation par la propagande pour faire oublier les importantes destructions causées au patrimoine monumental dans le nord et l'est de la France.

\section{La collection de fossiles d'Ernst Jünger (1917)}

L'existence de petites collections réalisées par les soldats eux-mêmes est attestée. Même s'il ne s'agit pas d'une découverte archéologique à proprement parler, il est intéressant de mentionner la collection de fossiles de l'écrivain allemand Ernst Jünger (1895-1998). Celle-ci fut constituée dans le secteur du « Bois-le-Prêtre » à proximité de Thiaucourt-Regniéville (Meurthe-et-Moselle) en août-septembre 1917. 
Un géologue aurait été ravi de cette position. Les boyaux d'approche passaient successivement à travers six couches, du calcaire corallien à la «marne de Gravelotte ", où était creusée la tranchée de combat. La roche, d'un brun jaune, grouillait de fossiles : le plus fréquent était un oursin plat, en forme de petit pain, dont le test saillait par milliers aux parois de tranchée. Je ne pouvais traverser le secteur sans en rapporter dans mon abri plein mes poches de coquilles, d'oursins et d'ammonites ${ }^{145}$.

\section{Une activité archéologique dans les musées alsaciens malgré la guerre?}

Si le musée de Metz est fortement sollicité dans le cadre du Kunstschutz pour la protection et la mise à l'abri des œuvres menacées, l'activité du musée archéologique de Strasbourg se poursuit presque normalement dans une ville relativement abritée à l'arrière du front.

\section{Le musée préhistorique et gallo-romain de Strasbourg}

Outre son activité de terrain, au gré des circonstances et des découvertes, R. Forrer et la petite équipe réunie autour de lui continuent à faire vivre le musée durant toute la période de la guerre. Celle-ci est mise à profit pour ranger le fonds ancien des collections de la Société pour la Conservation des Monuments historiques d'Alsace, collections progressivement accumulées depuis la création de cette société savante régionale en 1855. Les objets non inventoriés sont inscrits à l'inventaire du musée en plusieurs vastes campagnes en 1915 et 1916 ; ils serviront de base au futur ouvrage sur Strasbourg (Argentorate) publié en deux volumineux tomes en $1927^{146}$, pour lequel R. Forrer engrange de nombreuses informations, tout en continuant à publier ses recherches dans les Anzeiger für Elsässische Altertumskunde dont il est le rédacteur en chef depuis 1909.

Une autre tâche de classement et d'étude est poursuivie en parallèle, portant sur le mobilier issu des fouilles d'un sanctuaire mithriaque au cours de l'hiver 1911-1912 dans le faubourg de Koenigshoffen, près de Strasbourg, lors des travaux de construction de la nouvelle église Saint-Paul. Les fouilles dirigées par R. Forrer avaient permis d'établir le plan du sanctuaire et de recueillir pour le musée de nombreux fragments sculptés, dont un nombre important se rattache à un grand relief cultuel mettant en scène le dieu Mithra sacrifiant un taureau. Les premières années de la guerre sont ainsi employées par R. Forrer pour étudier et inventorier l'impressionnant ensemble de mobilier archéologique livré par la fouille. Ce travail aboutit à une publication scientifique, dédiée au maire de Strasbourg Rudolf Schwander (1868-1950) ${ }^{147}$, parue en 1915 dans les Mitteilungen der Gesellschaft für Erhaltung der Geschichtlichen Denkmäler im Elsass (Bulletins de la Société pour la Conservation des Monuments historiques d'Alsace) ${ }^{148}$. Les vestiges les plus remarquables prennent place, quant à eux, dans l'une des salles du musée et une reconstitution du relief cultuel est réalisée à cette occasion. Elle intègre les fragments sculptés originaux dans un grand panneau dont la scène centrale est restituée et complétée en plâtre polychromé.

Un second manuscrit est préparé par R. Forrer au cours des années de guerre, aboutissant en 1918 à la publication des découvertes romaines de Saverne (Tres Tabernae) (Bas-Rhin) ${ }^{149}$. Si le projet initial était de publier l'enceinte romaine de Saverne 
dans le cadre d'un projet d'étude chronologique et comparative des fortifications dans le Rhin supérieur entre Vosges et Rhin, en incluant Strasbourg, Metz, Sarrebourg, Horbourg, la richesse des vestiges immobiliers et mobiliers livrés par le sous-sol savernois a fait évoluer le projet vers une synthèse sur le seul Saverne romain. La guerre est également responsable pour une part de l'abandon de la synthèse générale, comme l'indique R. Forrer dans la préface, les hostilités l'empêchant de se déplacer librement en Lorraine, en Haute-Alsace et dans les Vosges. Cette préface se termine d'ailleurs par ces quelques mots très explicites : «Strassburg, im vierten Kriegsjahr, 1918 » (Strasbourg, quatrième année de guerre, 1918).

\section{Le Musée historique de Mulhouse : un musée à proximité de la zone de combats}

Pendant l'été 1914, le Musée historique de Mulhouse, en travaux pour mieux présenter ses riches collections archéologiques et historiques, voit son chantier interrompu par l'imminence de la guerre. Les objets les plus précieux sont déposés dans un caveau de la Banque d'Alsace et de Lorraine le 5 août 1914 et y séjournent jusqu'à l'armistice, en novembre 1918.

Lors de la première bataille de Mulhouse, les 9 et 10 août 1914, et dans l'affolement qui s'empara des troupes allemandes dans la nuit du 10 au 11 août et qui les porta à tirer dans toute la ville sans rime ni raison, bien des projectiles tombèrent sur le toit du Musée, en y occasionnant de légers dégâts. Quand les Français occupèrent Mulhouse pour la seconde fois, le 19 août 1914, un détachement de soldats du $42^{\mathrm{e}}$ régiment d'infanterie se logèrent au Musée, où ils couchèrent sur de la paille au rez-de-chaussée. Quelques-uns d'entre eux vinrent visiter le Musée historique et inscrivirent leur nom au registre déposé dans la salle. Ils repartirent, sans prévenir personne, dans la nuit du 24 au 25 août, en abandonnant quelques effets, que nous conserverons au Musée comme souvenirs de guerre. Nous voulions faire de même pour un fusil, qui était resté également ; mais, au retour des Allemands, la chose fut jugée trop dangereuse, et le fusil dut faire un plongeon dans le canal ${ }^{150}$.

En mars 1915, l'installation au rez-de-chaussée d'un hôpital provisoire pour les malades et les blessés est faite sur proposition du président de la Société de la Croix-Rouge à la Société Industrielle de Mulhouse, propriétaire des lieux.

Tout comme à Strasbourg, l'activité se réduit en 1917 et 1918 au classement de l'importante collection archéologique donnée par Frédéric Engel-Dollfus (1818-1883) au musée. C'est Léonard-Georges Werner (1874-1950), qui en devient le conservateur en janvier 1919, qui entreprend ce travail.

\section{Épilogue}

Le réexamen des découvertes archéologiques réalisées pendant la Grande Guerre en Alsace et en Lorraine met donc en évidence une surreprésentation des découvertes réalisées dans les lignes allemandes. Même si quelques observations françaises peuvent être mentionnées en Lorraine, elles n'ont jamais fait l'objet de publications scientifiques par leurs découvreurs. Cette observation ne doit cependant pas être généralisée à l'ensemble du front comme le démontrent, par exemple, certaines découvertes du nord de la France ou du front oriental. 
Les découvertes réalisées du côté allemand bénéficient bien souvent de notes plus ou moins longues (Grandfontaine, Norroy-lès-Pont-à-Mousson, etc.), voire de publications monographiques (Senon). Le travail des responsables des musées allemands de Metz et de Strasbourg doit être souligné. La façon dont les observations ont été menées par Johann Baptist Keune et Robert Forrer laisse cependant apparaître quelques différences dans leur approche du terrain. Cela est peut-être à mettre au compte des difficultés d'accès aux sites en pleine zone militaire, mais aussi probablement d'une conception un peu différente de l'archéologie. R. Forrer, très attaché à l'observation directe du terrain et pionnier dans le domaine de la recherche sur le Néolithique et la Protohistoire en Alsace, attache une grande importance aux vestiges de toutes périodes, même aux plus infimes. À chaque fois que cela est possible, il effectue des relevés, croquis et descriptions pour garder trace du contexte des découvertes ou tente d'obtenir des informations auprès des autorités militaires.

En revanche, en Lorraine, la formation de J. B. Keune et sa mission de protection des œuvres menacées dans la zone de front l'amènent essentiellement à s'intéresser et à sauvegarder les monuments les plus marquants; les découvertes pour lesquelles il est intervenu concernent ainsi en premier chef des découvertes où des constructions ou des éléments lapidaires antiques et mérovingiens (sarcophages, autel, murs, etc.) ont été retrouvés. L'enregistrement des découvertes repose largement sur la photographie, avec un regard plus artistique que réellement archéologique. Ces clichés donnent souvent l'impression de souvenirs de voyages et il est probable qu'il ait réalisé, à partir de ses plaques, des tirages papier pour ceux qui l'accompagnaient, l'accueillaient ou le guidaient. J. B. Keune apparaît d'ailleurs très souvent sur les clichés, posant avec les inventeurs et les officiers à côté de leur découverte. Le nom de son opérateur photographique reste cependant inconnu, à moins qu'il ait disposé d'un appareil à déclenchement automatique différé ou utilisé le concours occasionnel de témoins après avoir lui-même procédé aux réglages. Quant aux légendes des clichés, elles sont, sinon absentes, très courtes. Les carnets de J. B. Keune, à peine exploités jusqu'à présent, ne lui servent qu'à prendre des notes, recopier des éléments épigraphiques ou noter des entrées d'objets. Ils apportent des éléments sur ses activités sans pour autant permettre de restituer l'ensemble de ses travaux. La recherche d'informations dans ces documents apporte rarement des éléments sur les contextes.

R. Forrer continue après le conflit à présider aux destinées de la recherche archéologique régionale et au musée dont il a la charge jusqu'à la veille de la Seconde Guerre mondiale. Il assure une grande stabilité et une continuité des recherches pour le plus grand profit des collections de la francophile Société pour la Conservation des Monuments historiques d'Alsace, en coordonnant une large partie de la recherche archéologique régionale jusqu'en 1939 et l'éclatement du second conflit mondial.

Malgré son importante implication dans la sauvegarde et l'étude du patrimoine régional, J. B. Keune est quant à lui démis de ses fonctions de directeur du musée de Metz le 19 novembre 1918 puis licencié le 31 janvier 1919. Après avoir été chargé de passer le relais à son successeur français, Roger Clément (1878-1950), dans une atmosphère devenue exécrable, il est expulsé définitivement le 5 octobre $1919^{151}$ J. B. Keune devient même l'objet d'accusations comme celle de détournement d'œuvres d'art dans la Meuse ou de participation à la propagande, notamment lors de l'exposition de 1917 à Metz. Malgré le soutien de son successeur et celui de nombreux savants français comme Émile Espérandieu (1857-1939), il retourne à Trèves où il 
s'installe, non sans difficultés. Devenu collaborateur du musée d'Archéologie romaine de la ville, il poursuit ses travaux et meurt le 12 janvier 1937.

À la suite de ces bouleversements politiques, le renouvellement des chercheurs qui en résulte n'est pas sans conséquences importantes sur la recherche archéologique dans l'entre-deux-guerres, tout particulièrement en Lorraine.

\section{NOTES}

1. - FORRER, Robert. «Elsässische Archäologie in den Schützengräben ». Mitteilungen des Rheinischen Vereins für Denkmalpflege und Heimatschutz, 15 September 1915, n², p. 106.

2. - LANDOLT, Michaël, SCHNITZLER, Bernadette. «Découvertes archéologiques pendant la Grande Guerre en Alsace ». Dans SCHNITZLER, Bernadette, LANDOLT, Michaël. À l'Est, du nouveau ! Archéologie de la Grande Guerre en Alsace et en Lorraine. Strasbourg: Musées de la Ville de Strasbourg, catalogue d'exposition, 2013, p. 46-49. MOUROT, Franck, LAPARRA, Jean-Claude. «L'archéologie pendant la Grande Guerre en Lorraine », Dans ibid., p. 53-56.

3. - SPINDLER, Charles. L'Alsace pendant la guerre. Strasbourg: Treuttel \& Würtz, 1925. BURTSCHER, Philippe. De la ceinture fortifiée de Strasbourg à la position de la Bruche 1870-1918. Mutzig: Cercle d'Étude des Fortifications/Société d'Histoire de Mutzig et environs, 1999.

4. - SPINDLER, Charles. L'Alsace pendant la guerre. Strasbourg : Treuttel \& Würtz, 1925, p. 65.

5. - FORRER, Robert. «Elsässische Archäologie in den Schützengräben ». Mitteilungen des Rheinischen Vereins für Denkmalpflege und Heimatschutz, 15 September 1915, n², p. 99-106.

6. - LANDOLT, Michaël, BOLLY, Alexandre, DECKER, Émile, LE BAILLY, Matthieu, LESJEAN, Frank, PUTELAT, Olivier. «L'occupation de la Première Guerre mondiale ». Dans LANDOLT, Michaël, ABERT, Franck, BOLLY, Alexandre. Entzheim "In der Klamm» et Geispolsheim "Schwobenfeld» (Alsace, Bas-Rhin) : les occupations historiques de l'époque gallo-romaine à la Seconde Guerre Mondiale. Rapport final d'opération de fouille. Sélestat: PAIR, 2013, p. 103-184. Aucune source textuelle ne fait part d'observations archéologiques réalisées sur le site pendant le conflit.

7. - Fichiers de la Carte archéologique de Lorraine, prospections aériennes (Service régional de l'Archéologie, DRAC Lorraine). MOUROT, Franck. La Meuse. Carte archéologique de la Gaule. Paris : Académie des Inscriptions et Belles-Lettres/Ministère de l'Éducation nationale/Ministère de la Recherche, 2001, p. 198, 299, 368, 480...

8. - Quelques exemples pour l'Alsace : Bas-Rhin : Grandfontaine «Donon » vers le massif vosgien, Haut-Rhin : Hartmannswiller vers la plaine d'Alsace, Illfurth « Britzgyberg » vers la vallée de l'Ill et la trouée de Belfort, Kœstlach-Mœrnach « Kastelberg » vers la trouée de Belfort.

9. - Tels les châteaux de Wintzenheim « Hohlandsberg ", " Pflixbourg », Labaroche « Hohnack", Hattstatt «Haut-Hattstatt», Griesbach-au-Val «Schwarzenbourg» dans le Haut-Rhin. Voir $\mathrm{KOCH}$, Jacky. "De l'usage stratégique de la ruine de château fort: la reconversion de quelques sites de châteaux du Val Saint-Grégoire (Haut-Rhin) ». Dans SCHNITZLER, Bernadette, LANDOLT, Michaël. op. cit., 2013, p. 63-64.

10. - LIÉNARD, Félix. "L'Homme de Cumières pendant l'époque néolithique (âge du renne)». Mémoires de la Société Philomatique de Verdun, 1874, t. 8, p. 5-54.

11. - CHENET, Georges. «L'industrie céramique gallo-belge et gallo-romaine en Argonne ». Revue des Études Anciennes, 1938, t. 40, p. 271-272. 
12. - LEHNER, Hans. « Über einige Altertumsfunde von der Westfront ». Bonner Jahrbücher, 1916, $\mathrm{n}^{\circ} 123$, p. 264-274.

13. - LEHNER, Hans. "Streifzüge in der Reimser Champagne ». Champagne-Zeitung, 27 mai 1916, $\mathrm{n}^{\circ} 121$, p. 738 et suivantes.

14. - LEHNER, Hans, op. cit., 1916, p. 271-274.

15. - KOEPP, Friedrich. «Bericht über die Tätigkeit der Römisch-Germanische Kommission im Jahre 1917 ». Bericht der Römisch-Germanischen Kommission, 1917, n¹0, p. 5.

16. - LIÉNARD, Félix. Archéologie de la Meuse. Volume 3 : Description des voies anciennes et des monuments aux époques celtique et gallo-romaine. Verdun : Imprimerie Charles Laurent, 1885, p. 56. MOUROT, Franck. op. cit., 2001, p. 265.

17. - Par exemple dans la rubrique « Numismatique des Tranchées " (Archives du Service Historique de la Défense, Vincennes).

18. - BAUDOUIN, Marcel. «La Préhistoire dans les Tranchées ». Bulletin de la Société Préhistorique Française, 1915, t. 12, nº, p. 275.

19. - BOSSAVY, Jules. "Les trouvailles dans les Tranchées ». Bulletin de la Société Préhistorique Française, 1915, t. 13, n5, p. 251.

20. - DESFOSSÉS, Yves, JACQUES, Alain, PRILAUX, Gilles. L'archéologie de la Grande Guerre. OuestFrance/Inrap : Rennes, 2008, p. 18-19.

21. - BAUDOUIN, Marcel. «Rapport de M. le Secrétaire général sur la situation orale et la gestion du conseil d'administration en 1917 de la Société Préhistorique Française ». Bulletin de la Société Préhistorique Française, 1918, t. 15, n¹, p. 45.

22. - COUTIL, Léon. « Allée couverte de Vaudancourt (Oise) : fouilles de 1918-1919, exécutées pour la Société Préhistorique Française. Étude sur les allées couvertes avec cloisons perforées de l'Oise, Seine-et-Oise et de l'Europe ». Mémoires de la Société Préhistorique Française, 1919, t. 4.

23. - HÉMERY, Marcel. « Découvertes d'objets de l'époque gauloise à Tracy-le-Val (Oise), au cours de travaux militaires ». Bulletin de la Société Préhistorique Française, 1915, t. 12, n¹0, p. 421-422.

24. - REYNIER, Philippe. «La préhistoire des tranchées dans le canton de Lizy-sur-Ourcq (S.-etM.) ». Bulletin de la Société Préhistorique Française, 1915, t. 12, n5, p. 245-246.

25. - TRASSAGNAC, Paul. "Fouilles dans les tranchées militaires". Bulletin de la Société Préhistorique Française, 1915, t.12, n5, p. 244-245. TRASSAGNAC, Paul. «Notes sur quelques fouilles pratiquées dans les tranchées ». Bulletin de la Société Préhistorique Française, 1915, t. 12, n7, p. 331-342. TRASSAGNAC, Paul. «Recherches nouvelles faites dans les Tranchées ». Bulletin de la Société Préhistorique Française, 1916, t. 13, n², p. 99-102.

26. - TRASSAGNAC, Paul, op. cit., 1915, t.12, n7, p. 331. VIRÉ, Armand. " Notes de guerre Préhistoire et archéologie dans les tranchées d'Artois en 1915 ». Bulletin de la Société Préhistorique Française, 1920, t. 17, n², p. 64.

27. - HUBER, Henri. « La Préhistoire et les Tranchées ». Bulletin de la Société Préhistorique Française, 1915, t. $12, n^{\circ} 2$, p. 68-69.

28. - VIRÉ, Armand, op. cit., p. 57-64.

29. - BARBUSSE, Henri. Le Feu. Journal d'une escouade. Paris : Flammarion, 1916, p. 12.

30. - KREMPF, Thérèse. « Les fouilles archéologiques de l'armée d'Orient 1915-1918 ». Cahiers de la Grande Guerre, 2004, n³1, p. 103-119.

31. - PLANCOUARD, Léon. "Communication sur une trouvaille de monnaies par les soldats de Verdun ». Bulletin Archéologique du Comité des travaux historiques et scientifiques, 1917, p. 127.

32. - Des monnaies de la fin du III ${ }^{\mathrm{e}}$ siècle (Claude le Gothique, Gallien et Tetricus), du XIII ${ }^{\mathrm{e}}$ siècle (Philippe III de France) et du XVI ${ }^{\mathrm{e}}$ siècle/début du XVII ${ }^{\mathrm{e}}$ siècle (Philippe II d'Espagne et ses successeurs) et des jetons des Pays-Bas.

33. - Anonyme. «De l'utilité de la Revue des Musées ». Revue des Musées et collections archéologiques, 1928, n¹5, p. 75. CHENET, Georges. "Un four de gobeletier gallo-romain des Allieux près de Vauquois (Meuse) ». Revue des Musées et collections archéologiques, 1929, n²0, p. 48-52. Les Journaux 
des marches et opérations français des différents régiments ne sont pas conservés ou ne mentionnent pas ces découvertes.

34. - La $19^{\mathrm{e}}$ brigade appartient à la $10^{\mathrm{e}}$ division d'infanterie. Celle-ci occupe un secteur à proximité de Vauquois entre octobre et début novembre 1914, puis du 14 février 1915 au $1^{\text {er }}$ août 1916. Il est intéressant de souligner que le colonel Henri Pinoteau écrivit à la veuve de l'archéologue français Joseph Déchelette (1862-1914), pour témoigner des dernières paroles de son mari tué le 4 octobre à Vingré (Aisne) (Bibliothèque de Roanne, M1020-AJDL-V43).

35. - Louis Gain participa aux expéditions polaires en Antarctique avec l'explorateur JeanBaptiste Charcot (1867-1936). Le $46^{\mathrm{e}}$ régiment d'infanterie (19 $\mathrm{e}$ brigade, $10^{\mathrm{e}}$ division d'infanterie) se trouve à Vauquois de mars 1915 à juillet 1916.

36. - CHENET, Georges, op. cit., 1929, n²0, p. 48.

37. - Le $4^{\mathrm{e}}$ régiment d'infanterie, cité dans la publication de 1929 , n'est cependant pas présent à Vauquois entre avril et mai 1915 (CHENET, Georges, op. cit., 1929, n²0, p. 48). Cette unité appartient à la $17^{\mathrm{e}}$ brigade ( $9^{\mathrm{e}}$ division d'infanterie), présente en Argonne, qui participe aux attaques de la "Haute-Chevauchée " à Lachalade entre avril et juillet 1915 puis à Boureuilles "Côte 263 ». Par contre le $76^{\mathrm{e}}$ régiment d'infanterie appartient à la $20^{\mathrm{e}}$ brigade $\left(10^{\mathrm{e}}\right.$ division d'infanterie), stationné en Argonne de novembre 1914 à juillet 1915, qui est présent à Vauquois de février à juin 1915.

38. - Anonyme. «Vauquois ». Revue des Musées et collections archéologiques, 1928, n¹4, p. 59.

39. - CHENET, Georges, op. cit., 1929, n²0, p. 49, fig. 1. CHENET, Georges, op. cit., 1938, t. 40, p. 271-272. CHENET, Georges, GAUDRON, Guy. La céramique sigillée d'Argonne des II et $\mathrm{III}^{e}$ siècles. Paris : CNRS, 1955, Supplément à Gallia, 6, p. 61-73.

40. - Anonyme, op. cit., 1928, n¹5, p. 75.

41. - CHENET, Georges, op. cit., 1929, n²0, p. 52.

42. - CHENET, Georges, op. cit., 1929, n²0, p. 51.

43. - TOUSSAINT, Maurice. Répertoire archéologique du département de la Meuse (période galloromaine). Bar-le-Duc : Imprimerie Contrant-Laguerre, 1946. MOUROT, Franck, op. cit., 2001, p. 153. 44. - LANDOLT, Michaël. «Georges Goury (1875-1959) : un archéologue lorrain en exil et une collection archéologique détruite par la guerre». Dans SCHNITZLER, Bernadette, LANDOLT, Michaël, op. cit., 2013, p. 60-61.

45. - KOTT, Christina. Préserver l'art de l'ennemi. Le patrimoine artistique en Belgique et en France occupée 1914-1918. Bruxelles/Bern/Berlin : Peter Lang, 2006, p. 42-45.

46. - DESFOSSÉS, Yves, JACQUES, Alain, PRILAUX, Gilles, op. cit., 2008, p. 19. NIGGEMANN, Hans, BRETON, Cécile, DEMOULE, Jean-Paul, DESENNE, Sophie. «VIII - Les fouilles allemandes de 1915 ». Dans DESENNE, Sophie, POMMEPUY, Claudine, DEMOULE, Jean-Paul, et al.. « Bucy-le-Long. Une nécropole de la Tène ancienne ( $\mathrm{V}^{\mathrm{e}}-\mathrm{IV}^{\mathrm{e}}$ siècle avant notre ère) ». Revue Archéologique de Picardie, Staatliche Museum zu Berlin: Amiens, vol.2, p.515-621. Numéro spécial de la Revue Archéologique de Picardie, 26, 2009.

47. - LANDOLT, Michaël. « Karl Sebastian Gutmann (1854-1931)». Dans SCHNITZLER, Bernadette, LANDOLT, Michaël, op. cit., 2013, p. 52.

48. - GUTMANN, Karl Sebastian. "Keltisch-helvetische Siedlung von Hochstetten ». Römischgermanisches Korrespondenzblatt, Mai-Juni 1917, n³, p. 71-78.

49. - FORRER, Robert. « Die Fortschritte der prähistorischen und römischen Forschung im Elsass 1913-1925». Bericht der Römisch-Germanische Kommission, 1926, n¹5, p. 67-122. SCHNITZLER, Bernadette. Robert Forrer (1866-1947) archéologue, écrivain et antiquaire. Strasbourg : Société Savante d'Alsace/Musées de Strasbourg, 1999, Recherches et documents, 65. SCHNITZLER, Bernadette. « Robert Forrer (1866-1947) ». Dans SCHNITZLER, Bernadette, LANDOLT, Michaël, op. cit., 2013, p. 50-51.

50. - FORRER, Robert, op. cit., 15 September 1915, p. 99-106. FORRER, Robert. « Caves et fonds de cabanes préhistoriques en Alsace». Bulletin archéologique du Comité des travaux historiques et 
scientifiques, 1921, p. 9 : «Lors de la guerre de 1914-1918, j'ai visité, en ma qualité de conservateur du Musée, les tranchées militaires pour les étudier en relation avec les fonds de cabanes ". D'après René DEBRIX (1881-1955), l'archéologue pourrait même s'être adressé directement à un membre de la famille de Wurtemberg, mais l'intérêt et la véracité de cette demande restent à vérifier car la procédure n'est pas a priori pertinente. À cette période, le duc de Wurtemberg ne commandait pas le détachement d'armée $\mathrm{A}$ (Armee-Abteilung $A$ ) qui avait son quartier général à Strasbourg. Voir SCHNITZLER, Bernadette. La Passion de l'Antiquité. Six siècles de recherches archéologiques en Alsace. Strasbourg: Société Savante d'Alsace/Musées de Strasbourg, 1998, Recherches et documents, 60, p. 139.

51. - SCHNITZLER, Bernadette. Robert Forrer (1866-1947) archéologue, écrivain et antiquaire. Strasbourg : Société Savante d'Alsace/Musées de Strasbourg, 1999, Recherches et documents, 65, p. 109.

52. - FORRER, Robert. «Ein Münzschatzfund bei Sand in Baden aus der Zeit der Alemanneneinfälle ». Badische Fundberichte, November 1926, n6, p. 188-189.

53. - WALTHER. Notes et correspondances sur l'atelier de Cheppy, manuscrit, musée archéologique de Strasbourg, $\mathrm{n}^{\circ}$ d'inv. 18525.

54. - FORRER, Robert. « Die römischen Terrasigillata-Töpfereien von Heiligenberg-Dinsheim und Ittenweiler im Elsass ». Mitteilungen der Gesellschaft für Erhaltung der Geschichtlichen Denkmäler im Elsass, 1911, t. 23, p. 528-768.

55. - Cette découverte inédite n'est pas référencée dans l'inventaire des découvertes de cette commune. Voir DELMAIRE, Roland, JACQUES, Alain, LEMAN-DELERIVE, Germaine, SEILLIER, Claude. Le Pas-de-Calais 62/2. Carte archéologique de la Gaule. Paris: Académie des Inscriptions et Belles-Lettres/Ministère de la Recherche, 1993, p. 414-415.

56. - Musée archéologique de Strasbourg, $\mathrm{n}^{\circ}$ d'inv. 29313.

57. - KOTT, Christina, op. cit., 2006, p. 244-248. BARDIÈS, Isabelle. « Le Professor Keune, conservateur allemand dans la guerre ». Dans BARDIÈS, Isabelle, COLLANGES, Françoise, FAURESPANIER, Sylvie, LAPARRA, Jean-Claude. De la frontière au front. Un point de vue allemand. Campagnes photographiques 1914/1917. Metz: Musées de la Cour d'Or, 2003, p. 15-21; LAPARRA, Jean-Claude. "Johann Baptist Keune, directeur du musée de Metz (1899-1918) : un Allemand si lorrain ». Les Cahiers lorrains, juin 2009, n¹-2, p. 22-37. LAPARRA, Jean-Claude. "Johann Baptist Keune (1858-1937): un archéologue allemand sur le front lorrain». Dans SCHNITZLER, Bernadette, LANDOLT, Michaël, op. cit., 2013, p. 57-58.

58. - COLLANGES, Françoise. « Le fonds photographique du musée de Metz de 1870 à 1918 : source historique ou instrument de propagande». Dans BARDIÈS, Isabelle, COLLANGES, Françoise, FAURE-SPANIER, Sylvie, LAPARRA, Jean-Claude, op. cit., 2003, p. 6-13.

59. - TOUSSAINT, Maurice. Répertoire archéologique du département de la Meurthe-et-Moselle (période gallo-romaine). Nancy : Société d'impressions typographiques, 1947, p. 43-46.

60. - KEUNE, Johann Baptist. Kriegsarbeit des Museums zu Metz. Metz : Even, 1916.

61. - KOTT, Christina. «Histoire de l'art et propagande pendant la Première Guerre mondiale. L'exemple des historiens d'art allemands en France et en Belgique». Revue germanique internationale, $2000, \mathrm{n}^{\circ} 13$, p. 201-221.

62. - Heribert Reiners est le fils du célèbre peintre allemand Jakob Reiners (1828-1907).

63. - D'après les registres d'inventaires du musée archéologique de Strasbourg réalisés entre 1914 et 1918 .

64. - BURTSCHER, Philippe, op. cit., 1999.

65. - D'après R. Forrer, entre Mittelhausbergen et Pfulgriesheim : FORRER, Robert. « Un foyer de chasseurs de mammouths à Achenheim et les autres gisements paléolithiques de l'Alsace». Anzeiger für Elsässische Altertumskunde, mai 1920, n41-44, p.1136. Musée archéologique de Strasbourg, nº d'inv. 17215.

66. - Batteries 14 et 16 dans BURTSCHER, Philippe, op. cit., 1999, p. 397-402. 
67. - Le site localisé par erreur à Achenheim se trouve en fait sur la commune d'Oberschaeffolsheim. FORRER, Robert. « Nouvelles découvertes et acquisitions du Musée préhistorique et gallo-romain de Strasbourg ». Cahiers d'Archéologie et d'Histoire d'Alsace, décembre 1922, n49-52, p. 18. Musée archéologique de Strasbourg, nº d'inv. 17121.

68. - I 70 dans BURTSCHER, Philippe, op. cit., 1999, p. 412.

69. - Le site localisé par erreur à Dingsheim se trouve à Oberschaeffolsheim. FORRER, Robert. "Nouvelles découvertes et acquisitions du Musée préhistorique et gallo-romain de Strasbourg ». Cahiers d'Archéologie et d'Histoire d'Alsace, décembre 1922, n49-52, p. 19. Musée archéologique de Strasbourg, n d'inv. 17041 à 17062.

70. - I 57-58 et J I-III dans BURTSCHER, Philippe, op. cit., 1999, p. 404-407.

71. - FORRER, Robert. "Spondylus-Muschelschmuck der Steinzeit aus dem Elsass ». Anzeiger für Elsässische Altertumskunde, Oktober 1916, n²8-31, p. 717-719. Musée archéologique de Strasbourg, n d'inv. 17 118, 17119 et 17124 à 17127.

72. - FORRER, Robert, op. cit., décembre 1922, p. 12. Musée archéologique de Strasbourg, $\mathrm{n}^{\circ}$ d'inv. 17129 à 17134 .

73. - Musée archéologique de Strasbourg, nº d'inv. 17122.

74. - FORRER, Robert, op. cit., décembre 1922, p. 19-20.

75. - BURTSCHER, Philippe, op. cit., 1999, p. 459-460.

76. - FORRER, Robert, op. cit., décembre 1922, p. 27.

77. - Musée archéologique de Strasbourg, n d'inv. 32439.

78. - FORRER, Robert, op. cit., mai 1920, n³2, p. 1136. Musée archéologique de Strasbourg, $\mathrm{n}^{\circ}$ d'inv. 17128.

79. - Musée archéologique de Strasbourg, nº d'inv. 28063.

80. - Musée archéologique de Strasbourg, $\mathrm{n}^{\circ}$ d'inv. 17 040a à 17 040f.

81. - FORRER, Robert. «Grabfund bei Walbach im Oberelsass». Anzeiger für Elsässische Altertumskunde, August 1918, n³3-36, p. 980 (reprise d'un article de presse paru dans les Straßburger Neueste Nachrichten du 13 décembre 1914).

82. - Le site localisé par erreur à Achenheim se trouve à Oberschaeffolsheim. FORRER, Robert. "Caves et fonds de cabanes préhistoriques en Alsace ». Bulletin archéologique du Comité des travaux historiques et scientifiques, 1921, p. 11-26.

83. - HEINTZ, Georges-Frédéric. «Observations archéologiques à Achenheim-Bas de 1936 à 1952 ». Cahiers Alsaciens d'Histoire et d'Archéologie, 1953, n¹33, p. 53-66. HEINTZ, Georges-Frédéric. «Observations archéologiques à Achenheim-Bas de 1953 à 1963 ». Cahiers Alsaciens d'Histoire et d'Archéologie, 1964, n8, p. 55-70. L'auteur note la présence de tranchées et d'un abri d'infanterie bétonné de la Grande Guerre. Ceux-ci sont localisés sur le plan général de la fouille. En 2011, un diagnostic archéologique réalisé au nord de ce secteur à Oberschaeffolsheim « Gebreit » a permis d'étudier une position fortifiée identique. Voir FRANCISCO, Sébastien, BASOGE, Florian, HABASQUE, Audrey, et al. Achenheim (67) : déviation de Wolfisheim et Oberschaeffolsheim, liaison routière entre la RD45 et la RN4 2011, Rapport de diagnostic archéologique. Sélestat : Pair, 2011.

84. - Musée archéologique de Strasbourg, $n^{\circ}$ d'inv. 17 039a et $17039 \mathrm{~b}$.

85. - FORRER, Robert. « Nouvelles découvertes et acquisitions du Musée préhistorique et galloromain de Strasbourg ». Cahiers d'Archéologie et d'Histoire d'Alsace, 1923, n53-56, p. 95.

86. - I 74 dans BURTSCHER, Philippe, op. cit., 1999, p. 413-416.

87. - Musée archéologique de Strasbourg, n d'inv. 17 186-17 199.

88. - Musée archéologique de Strasbourg, $\mathrm{n}^{\circ}$ d'inv. 28 089. L'objet a été vendu au musée archéologique de Strasbourg en 1917 par le propriétaire du terrain. La céramique protohistorique retrouvée sur la commune, parfois rapprochée de cette découverte, avait été exhumée avant le conflit.

89. - FORRER, Robert. «Früh-Latène Gräber bei Bläsheim am Glöckelsberg ». Anzeiger für Elsässische Altertumskund, mai 1919, n³7-40, p.983-985. L'article date la découverte de 
janvier 1917 mais celle-ci date de janvier 1916 d'après les cahiers d'inventaires. Musée archéologique de Strasbourg, $n^{\circ}$ d'inv. 17343 à 17350.

90. - I 123 à I 126 dans BURTSCHER, Philippe, op. cit., 1999, p. 431-435.

91. - BURTSCHER, Philippe, op. cit., 1999, p. 411-412.

92. - SCHNITZLER, Bernadette, ARBOGAST, Béatrice, FREY, Annette. Les trouvailles mérovingiennes en Alsace. Tome 1: Bas-Rhin. Mainz: Verlag des Römisch-Germanischen Zentralmuseums, 2009, p. 11, Kataloge Vor- und frühgeschichtlicher Altertümer, t.41/1. Musée archéologique de Strasbourg, nº d'inv. 18664 à 18695.

93. - BURTSCHER, Philippe, op. cit., 1999, p. 460-462.

94. - SCHNITZLER, Bernadette, ARBOGAST, Béatrice, FREY, Annette, op. cit., 2009, p. 492. Musée archéologique de Strasbourg, n d'inv. 27267 à 27274.

95. - Ibid., p. 208. Musée archéologique de Strasbourg, nº d'inv. 18 008a.

96. - SCHNITZLER, Bernadette, ARBOGAST, Béatrice, FREY, Annette, op. cit., 2009, p. 208-209. Musée archéologique de Strasbourg, nº d'inv. 18001 à 18 008. BURTSCHER, Philippe, op. cit., 1999, p. 418-422.

97. - Anonyme. "Eine interessante Ausgrabung ». Strassburger Post, 15 Juni 1915. Après avoir dirigé des opérations en Alsace et en Lorraine dans le cadre de la $7^{\mathrm{e}}$ Armée dans l'été 1914 , le général von Schubert n'assure plus de commandement dans cette zone en 1915. Le 15 juin de cette année, il est à la tête du XXVII. Reservekorps dans les Flandres.

98. - SCHNITZLER, Bernadette, ARBOGAST, Béatrice, FREY, Annette, op. cit., 2009, p. 235. Musée archéologique de Strasbourg, n d'inv. 17151 et 29766.

99. - DENAIRE, Anthony, BARRAND-EMAM, Hélène, BROC, Émilie, et al.. Kolbsheim « Vogeseblick»: du village du Néolithique ancien à la position de la Bruche de 1914. Rapport final de fouille préventive. Strasbourg : Antea-Archéologie, 2013, 2 vol.

100. - I 20 dans BURTSCHER, Philippe, op. cit., 1999, p. 413-416.

101. - SCHNITZLER, Bernadette, ARBOGAST, Béatrice, FREY, Annette, op. cit., 2009, p. 154. Musée archéologique de Strasbourg, n d'inv. 27406 à 27 425. Les objets n'ont pas été individualisés par sépulture.

102. - I 72 dans BURTSCHER, Philippe, op. cit., 1999, p. 411-412.

103. - BURTSCHER, Philippe, op. cit., 1999, p. 464-476. Les sources mentionnent que la découverte est liée à l'implantation d'un « réservoir d'eau »; il s'agit cependant d'un abri bétonné pour un poste de commandement.

104. - Musée archéologique de Strasbourg, $n^{\circ}$ d'inv. 18222.

105. - Musée archéologique de Strasbourg, $n^{\circ}$ d'inv. 18009 et 18010.

106. - Le mobilier antique, lié à une occupation plus ancienne du secteur, se serait retrouvé dans la masse de la motte. BURNOUF, Joëlle. "Scharrach, château disparu». Dans Encyclopédie de l'Alsace, t. 11. Strasbourg : Éditions Publitotal, 1985, p. 6708.

107. - FORRER, Robert. «Des enceintes fortifiées préhistoriques, romaines et anhistoriques d'Alsace ». Bulletin de la Société pour la conservation des Monuments historiques d'Alsace, 1926, t. 26, p. 60 .

108. - Musée archéologique de Strasbourg, $n^{\circ}$ d'inv. 31312 et 31 312a. L'objet est entré dans les collections du musée archéologique de Strasbourg en juin 1917.

109. - BURTSCHER, Philippe, HOFF, François. Les fortifications allemandes d'Alsace-Lorraine, 1870-1918: de la défense des frontières à la Grande Guerre. Paris : Histoire et Collection, 2008, p. 40.

110. - PÖHLMANN, Fritz. "Grabungen auf der Hohen Donne (Donon)». Germania, MaiAugust 1918, n³-4, p. 89-93. LINCKENHELD, Émile. «Bericht über die Fortschritte der vor- und frühgeschichtlichen Forschung in Lothringen (1915-1928)». Bericht der Römisch-Germanischen Kommission, 1927, $\mathrm{n}^{\circ}$ 17, p. 122.

111. - Ipf dans le Bade-Wurtemberg, Eichstätt et Houbürg en Bavière.

112. - FORRER, Robert, op. cit., décembre 1923, p. 105. 
113. - FORRER, Robert. «Un char de culte à quatre roues et trône, découvert dans un tumulus gaulois à Ohnenheim (Alsace)». Cahiers d'Archéologie et d'Histoire d'Alsace, mai 1921, n45-48, p. 1195-1242.

114. - « Ils y avaient pratiqué pour cela, du côté sud-ouest, deux tranchées. L'une, large à sa base de $2 \mathrm{~m} 50$, en haut de 4 mètres, était longue de 33 mètres et allait jusqu'au sol du tumulus; l'autre de 7 mètres de largeur, coupait le talus sud en deux morceaux et avait pour but de donner libre accès aux projectiles dirigés sur la cible érigée au milieu de la grande tranchée. »

115. - « Ils [Les Bavarois] ramassèrent tant bien que mal tout ce qui se présentait à leurs yeux ».

116. - FORRER, Robert, op. cit., décembre 1923, p. 102-104.

117. - FORRER, Robert. Der Odilienberg, seine vorgeschichtlichen Denkmäler und mittelalterlichen Bauresten, seine Geschichten und seine Legenden. Strasbourg: K. J. Trübner, 1899. FORRER, Robert. Die Heidenmauer von St. Odilien; ihre prähistorischen Steinbrüche und Besiedlungsreste. Strasbourg: Schlesier und Schweikhardt, 1899.

118. - FORRER, Robert, op. cit., 1926, p. 37-40.

119. - FORRER, Robert, op. cit., 1915, p. 102 et fig. 19.

120. - WALTHER, op. cit., 1915. CHENET, Georges, op. cit., 1929, n²0, p. 52.

121. - GRIMM, Paul. «Zum Geleit ». Dans GRIMM, Paul. Varia Archaeologica Wilhelm Unverzagt zum 70. Geburtstag dargebracht. Berlin: Akademie-Verlag, 1964, p.3-5, Deutsche Akademie der Wissenschaften zu Berlin. Schriften der Sektion für Vor- und Frühgeschichte, 16. LEGENDRE, Jean-Pierre. «Wilhelm Unverzagt (1892-1971) et la céramique sigillée d'Argonne». Dans SCHNITZLER, Bernadette, LANDOLT, Michaël, op. cit., 2013, p. 59.

122. - CHENET, Georges, op. cit., 1929, n²0, p. 52.

123. - UNVERZAGT, Wilhelm. Terra sigillata mit Rädchenverziehung. Frankfurt-am-Rhein : Joseph Baer \& Co, 1919, Materialien zur römisch-germanischen Keramik, 3.

124. - CHENET, Georges. La Céramique gallo-romaine d'Argonne du IVe siècle et la terre sigillée décorée à la molette. Mâcon : Protat frères, 1941, Fouilles et documents d'archéologie antique en France, t. I. 125. - CHENET, Georges, op. cit., 1938, t. 40, p. 263-264, note 1. Il en est de même pour une partie des archives de son beau-père, le Dr. J. Meunier à Lavoye (Meuse).

126. - STROHM, G. « Eine spätrömische Glashütte in den Argonnen ». Germania, Januar-April 1920, $n^{\circ} 1 / 2$, p. 30-34. LOESCHCKE, Siegfried. «Zur angeblich römischen Glasshütte von St. Menehould in den Argonnen. Vergleischmaterial des 16. und 17. Jahrh. aus Trier ». Germania, April 1921, n¹, p. 35-43.

127. - CHENET, Georges. Buste-balsamaire du Princier (Pont-Verdunois) et bassin en bronze d'Avocourt. Pro Alésia, 1921, n³0, p. 145-160. CHENET, Georges, op. cit., 1929, n²0, p. 52.

128. - CHENET, Georges, op. cit., 1921, n³0, p. 146.

129. - CHENET, Georges, op. cit., 1921, n³0, p. 156-157. Voir aussi la coupe stratigraphique publiée par G. Chenet dans l'article (p. 157, fig. 6).

130. - Plus aucune trace de cette découverte n'existe au musée de Metz.

131. - Cette découverte, réalisée en décembre 1915 près de la Ferme de Leipzig (Hof Leipzig) n'était jusqu'à présent pas référencée dans les inventaires de la carte archéologique (Service régional de l'archéologie).

132. - LINCKENHELD, Émile, op. cit., 1927, p. 123-124, fig. 14.

133. - Anonyme. «Lothringen ». Römisch-germanisches Korrespondenzblatt, Juli-August $1915, \mathrm{n}^{\circ} 4$, p. 62.

134. - HANS, Elser. Bericht über einen Grab, Lager Varvinay, manuscrit, musée de Metz, 30 Mai 1915.

135. - GEORGES-LEROY, Murielle. Varvinay «Bois des Livrées» 1992. Rapport de sauvetage urgent. Metz : Service Régional de l'Archéologie, 1994.

136. - MOUROT, Franck, op. cit., 2001, p. 264. 
137. - Cette découverte généralement attribuée au $93^{\mathrm{e}}$ régiment d'infanterie de Landwehr pourrait initialement avoir été faite par le $1^{\mathrm{er}}$ régiment d'Ersatz de Landwehr, ce régiment s'étant trouvé dans le secteur au moment de la découverte.

138. - KEUNE, Johann Baptist. « Neue Funde. Hercules Saxetanus, eine Entdeckung unser Krieger bei Metz ». Römisch-germanisches Korrespondenzblatt, Mai-Juni 1916, n³, p. 38-41. LEHNER, Heinrich, op. cit., 1916, p. 268-274.

139. - KEUNE, Johann Baptist. «Zum Weihdenkmal des Hercules Saxetanus ». Römisch-germanische Kommission Korrespondenzblatt, März-April 1917, n², p. 59-60.

140. - KOTT, Christina, op. cit., 2006, p. 250-251.

141. - DREXEL, Friedrich. «Die Römer in Senon». Dans REINERS, Heribert. Eine Römersiedlung vor Verdun. München : F. Bruckmann, 1918, p. 16-33.

142. - Anonyme. «Archéologie préhistorique et gallo-romaine ». Bibliographie Lorraine 1926-1927, $1930, n^{\circ} 9$, p. 7.

143. - REINERS, Heribert, op. cit., 1918.

144. - CHENET, Georges. "L'établissement gallo-romain et le Bourge de Senon (Meuse). Les fouilles allemandes de 1917 à Senon ». Bulletin archéologique du Comité des travaux historiques et scientifiques, 1922, p. 126-144.

145. - JÜNGER, Ernst, traduit de l'allemand par PLARD, Henri. Orages d'acier. Journal de guerre, Le Livre de Poche. Paris : Christian Bourgeois Editeur, 2007 [1970], p. 239.

146. - FORRER, Robert. Strasbourg-Argentorate, préhistorique, gallo-romain et mérovingien. Strasbourg : Librairie Istra, 1927, 2 vol.

147. - Maire de Strasbourg entre 1906 et 1918.

148. - FORRER, Robert. « Das Mithra-Heiligtum von Königshofen bei Strassburg ». Mitteilungen der Gesellschaft für Erhaltung der Geschichtlichen Denkmäler im Elsass, 1915, t. 24, p. 1-134.

149. - FORRER, Robert. «Das römische Zabern Tres Tabernae ». Mitteilungen der Gesellschaft für Erhaltung der Geschichtlichen Denkmäler im Elsass, 1918, t. 25, p. 1-153.

150. - LUTZ, Jules. «Le Musée pendant la guerre 1914-1918». Bulletin du Musée historique de Mulhouse, 1914-1918, t. 38, p. 61-69.

151. - BARDIÈS, Isabelle, op. cit., 2003, p. 20-21.

\section{RÉSUMÉS}

Durant la Grande Guerre, des sites archéologiques sont découverts au hasard de l'aménagement d'ouvrages militaires et les belligérants réalisent diverses fouilles et observations. Ces opérations de «sauvetage » avant l'heure n'ont toutefois pas été menées partout dans des circonstances identiques en Alsace et en Lorraine. Même si cette observation ne peut pas être généralisée à l'ensemble du front, les travaux français sont dans ces régions souvent réalisés rapidement et font rarement l'objet de publications scientifiques. Les travaux allemands, en revanche, ont été plus méthodiques. Avec l'annexion de l'Alsace et de la Moselle en 1871, la structuration des musées de Metz (Moselle) et de Strasbourg (Bas-Rhin) permet de mettre en place une gestion des découvertes fortuites. Plusieurs archéologues interviennent dans ce cadre : Johann Baptist Keune (1858-1937) en Lorraine et Robert Forrer (1866-1947) en Alsace. Certaines découvertes font même l'objet de documentation photographique et sont largement diffusées à travers des publications parfois réalisées pendant les années de conflit. 
During the First World War, several archaeological sites were discovered by chance, during the construction of military fortifications. Both belligerent armies undertook various archaeological excavations and observations. These 'safeguarding' operations, like the emergency rescue excavations carried out today, were not undertaken in an identical manner in Alsace and in Lorraine. Although this observation cannot be held to be generally true for the whole of the front, in these two regions the French operations were often carried out hastily and were rarely the object of scientific publication. German work, on the other hand, was far more methodical. After the annexation of Alsace and the Moselle department in 1871, the structuration of museums at Metz (Moselle) and at Strasbourg (Bas-Rhin), made it possible to take these chance archaeological finds into account. Several archaeologists were active here, in particular Johann Baptist Keune (1858-1937) in Lorraine and Robert Forrer (1866-1947) in Alsace. Some discoveries were even the subject of photographic documentation and were widely communicated in publications, some of which even appeared during the wartime period.

\section{INDEX}

Mots-clés : archéologie, Première Guerre mondiale, Allemagne, France, Lorraine, Meurthe-etMoselle, Meuse, Moselle, Alsace, Bas-Rhin, Haut-Rhin, fortifications de campagne, tranchées, musées

\section{AUTEURS}

\section{MICHAËL LANDOLT}

Pôle d'Archéologie Interdépartemental Rhénan, UMR 7044 (Archimède), Strasbourg michael.landolt@pair-archeologie.fr

\section{BERNADETTE SCHNITZLER}

Musée archéologique de Strasbourg bernadette.schnitzler@strasbourg.eu

\section{JEAN-CLAUDE LAPARRA}

laparra.jean-claude@wanadoo.fr

\section{FRANCK MOUROT}

Conseil général de la Meuse, Conservation des Musées de la Meuse mourot.f@cg55.fr, fr.mourot@laposte.net

\section{JEAN-PIERRE LEGENDRE}

Direction régionale des Affaires culturelles de Rhône-Alpes, Service régional de l'Archéologie jean-pierre.legendre@culture.gouv.fr 